\title{
Covid-19 e igualdad de género
}

\section{Covid-19 and gender equality}

\author{
MARÍA Dolores FernándeZ GaLiño \\ Valedora do Pobo de Galicia \\ Magistrada en servicios especiales de la Audiencia \\ Provincial de A Coruña \\ ORCID ID: 0000-0002-7348-4339 \\ José FERnANDo LousADA ARochenA \\ Magistrado especialista de lo social - TSJ/Galicia \\ Profesor asociado de Derecho Procesal Universidad \\ de A Coruña \\ ORCID ID: 0000-0002-4629-0539
}

Recibido: 25/1/2021

Aceptado: $10 / 2 / 2021$

doi: https://doi.org/10.20318/femeris.2021.6137

Resumen: El estudio analiza el impacto de género de la pandemia causada por el coronavirus COVID-19 y la respuesta dada en España analizada desde una perspectiva de género. Para ello, se hace un triple acercamiento: (1) las consecuencias de la enfermedad sobre la salud de las personas; (2) las consecuencias del confinamiento y medidas acordadas para combatir la enfermedad; (3) las consecuencias sociales, laborales y económicas derivadas de la enfermedad y/o de las medidas para combatirla. Se alcanzan dos conclusiones: una, la pandemia pone en riesgo el nivel de igualdad de género alcanzado con anterioridad; y otra, pero también es oportunidad de mejora si los poderes públicos introducen la perspectiva de género en el corazón de la reconstrucción.

Palabras clave: COVID-19; igualdad de género; análisis en perspectiva de género del derecho español antipandemia.

Abstract: The study analyzes the gender impact of the pandemic caused by the COVID-19 coronavirus and the response given in spanish law analyzed from a gender perspective. For this, a triple approach is made: (1) the consequences of the disease on people's health; (2) the consequences of confinement and agreed measures to combat the disease; (3) the social, labor and economic consequences derived from the disease and / or the measures to combat it. Two conclusions are reached: one, the pandemic puts at risk the level of gender equality achieved previously; and another, but it is also an opportunity for improvement if the public powers introduce the gender perspective at the heart of reconstruction.

Keywords: COVID-19; gender equality; gender perspective analysis of Spanish anti-pandemic Law. 
“No olvidéis jamás que bastará una crisis política, económica o religiosa para que los derechos de las mujeres vuelvan a ser cuestionados. Estos derechos nunca se dan por adquiridos, debéis permanecer vigilantes toda vuestra vida"

SIMONE DE BEAUVOIR

\section{Derecho de los desastres, igualdad de género y consecuencias de la pandemia Covid-19}

\subsection{Derecho de los desastres e igualdad de género}

Definido el desastre como una disrupción grave del funcionamiento de una comunidad o sociedad en cualquier escala debida a fenómenos peligrosos que interaccionan con las condiciones de exposición, vulnerabilidad y capacidad, ocasionando pérdidas e impactos humanos, materiales, económicos y/o ambientales ${ }^{1}$, los desastres, sean naturales (terremotos, inundaciones o erupciones volcánicas; epidemias) o sean causados por los seres humanos (conflictos bélicos, guerras civiles), han acompañado siempre a la Humanidad. De ahí la existencia de estudios interdisciplinares sobre sus efectos económicos, sociales, demográficos, sanitarios, políticos ... y por supuesto, también jurídicos, al extremo de hablarse de un derecho de los desastres (disaster's law). Y si algo se ha aprendido de la Historia y es algo en lo cual coinciden todos los estudios sobre los desastres, es que en un desastre se comprometen los derechos humanos. Justamente la salvaguarda de los derechos humanos en situación de desastre y post-desastre es el tema estrella del derecho de los desastres.

En particular, el derecho de los desastres se preocupa por la igualdad de mujeres y hombres: los desastres ponen a las mujeres, en cuanto dispensadoras principales de cuidados según los roles tradicionales de género, como cuidadoras en la primera línea (frontline caregivers); las consecuencias socioeconómicas de los desastres se ceban especialmente en las mujeres dado su menor empoderamiento social y económico incrementando la situación previa de discriminación; los desastres son caldo de cultivo para la violencia de género en todas sus manifestaciones; en suma, los desastres propician los retrocesos en la igualdad de género.

La preocupación por el impacto de género de los desastres la podemos encontrar en la Plataforma para la Acción aprobada en la IV Conferencia Mundial de Beijing (1995), principalmente en relación con la mujer y los conflictos armados, que se catalogaba como esfera de especial preocupación (apartados 131 a 149). Menos espacio ocupaba la preocupación por los desastres naturales acaso debido a que en 1995 no estaban presentes macrodesastres como el Tsunami del Océano Indico de 2004, o el Huracán Katrina del Océano Atlántico de 2005. Pero, aún sin tanto espacio, se alertaba, dentro del marco gene-

\footnotetext{
${ }^{1}$ Se trata de una definición de desastre acordada y habitualmente usada a nivel internacional. En este sentido, la encontramos en el apartado 2 (sobre definiciones) de la Recomendación 205 sobre el empleo y el trabajo decente para la paz y la resiliencia de la Organización Internacional del Trabajo (2017).
} 
ral de presentación de las esferas de especial protección, acerca de que muchas mujeres se ven, además, particularmente afectadas por desastres ambientales (numeral 46).

Más específicamente, el Comité para la eliminación de todas las formas de discriminación contra la mujer (CEDAW) ha destacado, en el apartado 11 de su Recomendación General núm. 28 sobre las obligaciones básicas de los Estados Partes en virtud del artículo 2 de la Convención sobre la eliminación de todas las formas de discriminación contra la Mujer (2010), que las obligaciones de los Estados partes no cesan en períodos de conflicto armado ni en los estados de emergencia declarados por acontecimientos políticos o desastres naturales, agregando que estas situaciones tienen importantes repercusiones y consecuencias para el goce y el ejercicio de los derechos fundamentales de la mujer en pie de igualdad con el hombre, y también que los Estados partes deberían adoptar estrategias y tomar medidas para satisfacer las necesidades particulares de las mujeres en tiempos de conflicto armado y estados de emergencia.

Otro instrumento de interés es la Recomendación 205 sobre el empleo y el trabajo decente para la paz y la resiliencia de la Organización Internacional del Trabajo (2017); en su preámbulo se afirma considerar la necesidad de reconocer que las crisis afectan de manera distinta a las mujeres y a los hombres, y la importancia decisiva de la igualdad de género y el empoderamiento de las mujeres y las niñas para promover la paz, prevenir las crisis, posibilitar la recuperación y potenciar la resiliencia ${ }^{2}$, entendiendo la resiliencia como la capacidad que tiene un sistema, una comunidad o una sociedad expuestos a una amenaza para resistir, absorber, adaptarse, transformarse y recuperarse de sus efectos de manera oportuna y eficiente, en particular mediante la preservación y la restauración de sus estructuras y funciones básicas por conducto de la gestión de riesgos.

\subsection{Impacto de género de la pandemia COVID-19}

Como desastre que es, la pandemia causada por el coronavirus COVID-19 también responde a estas consideraciones, y siéndolo además a nivel mundial, esas consideraciones se podrían proyectar sobre la situación de cualquier nación. Por ello, la necesidad de analizar a nivel nacional y a nivel universal el impacto de género de la pandemia causada

\footnotetext{
${ }^{2}$ Consideraciones con concreción en el apartado 15 de la Recomendación, que, aunque redactado en 2017, presenta una actualidad en lo relativo a la igualdad de género que justifica su parcial reproducción: "En sus respuestas a la discriminación derivada de conflictos o desastres o agravada por estos, y al tomar medidas para promover la paz, prevenir las crisis, posibilitar la recuperación y potenciar la resiliencia, los Miembros deberían: (a) respetar, promover y hacer realidad la igualdad de oportunidades y de trato entre mujeres y hombres, sin discriminación de ningún tipo, teniendo en cuenta el Convenio núm. 100 y la Recomendación núm. 90 sobre igualdad de remuneración, 1951, y el Convenio núm. 111 y la Recomendación núm. 111 sobre la discriminación (empleo y ocupación), 1958; (b) prestar una atención especial a los hogares encabezados por una sola persona, en particular si se trata de niños y niñas, mujeres, personas con discapacidad o personas de edad; (c) adoptar medidas para asegurar que las mujeres que hayan ocupado un empleo durante una crisis y asumido mayores responsabilidades no sean reemplazadas contra su voluntad cuando regrese la mano de obra masculina; (d) adoptar medidas para velar por que las mujeres estén facultadas para participar de forma eficaz y significativa en los procesos de toma de decisiones en el contexto de la recuperación y la creación de resiliencia, se dé prioridad a sus necesidades e intereses en las estrategias y respuestas, y se promuevan y protejan los derechos humanos de las mujeres y las niñas; (e) prevenir y sancionar todas las formas de violencia por razones de género, con inclusión de la violación, la explotación sexual y el acoso sexual, y proteger y dar apoyo a las víctimas ...."
} 
por el COVID-19 ya ha sido destacada por los organismos internacionales, europeos, nacionales y autonómicos implicados en la igualdad de género. Sin ánimo de agotar todas las acciones realizadas por todos esos organismos (lo que sería una misión imposible dada la multiplicidad de organismos unido al compromiso demostrado por todos ellos en orden a la lucha contra la pandemia con perspectiva de género), vamos a destacar seguidamente algunas acciones de organismos de igualdad destacados.

- UN Women / ONU Mujeres, entre otras acciones, ha apuntado desde un primer momento la idea de que el coronavirus golpea tres veces a las mujeres: por la salud, por la violencia doméstica y por cuidar a los otros, ha elaborado una propuesta de programa mundial "Prevención y gestión de la pandemia del COVID-19 con perspectiva de género: de la respuesta de emergencia a la recuperación y la resiliencia ${ }^{\prime 3}$, y ha diseñado una respuesta rápida y específica para mitigar el impacto de la crisis de la COVID-19 en las mujeres y las niñas y garantizar que la recuperación a largo plazo las beneficie, una respuesta basada en 5 prioridades: mitigar y reducir la violencia de género, incluida la violencia doméstica; protección social y paquetes de estímulo económico que tengan en cuenta a las mujeres y las niñas; conseguir que las personas apoyen y practiquen el reparto equitativo del trabajo de cuidados; liderazgo y participación de las mujeres y las niñas en la planificación y toma de decisiones de la respuesta ante el COVID-19; datos y mecanismos de coordinación que incluyan perspectiva de género ${ }^{4}$.

- El Comité para la eliminación de todas las formas de discriminación contra la mujer (CEDAW) ha redactado un "Llamamiento a la acción conjunta en los tiempos de la pandemia COVID-19"5, en el cual solicita a los estados que intenten aprovechar este momento de la historia humana y procuran tratarlo como oportunidad para adoptar estrategias transformadoras que se basen en el empoderamiento y liderazgo de la mujer, sobre todo en los campos de las tecnologías digitales y la inteligencia artificial, y en última instancia, los estados deben salir de la crisis del COVID-19 más solidarios, respetando las normas de derechos humanos y promoviendo la gobernanza inclusiva, la justicia social y la paz; así como unas "Directrices sobre el CEDAW y COVID-19"7 donde se insta a los Estados parte a: (1) abordar el impacto desproporcionado de la pandemia en la salud de la mujer, (2) garantizar los servicios de salud sexual y reproductiva en tanto servicios sociales, (3) proteger a las mujeres y niñas de la violencia de género, (4) asegurar la igualdad de participación en la adopción de decisiones, (5) garantizar la educación continua, (6) proporcionar apoyos socioeconómicos a las mujeres, (7)

\footnotetext{
${ }^{3}$ https://www.unwomen.org/-/media/headquarters/attachments/sections/news\%20and\%20events/in\%20focus/ covid-19/gender-responsive-prevention-management-covid19.pdf?la=es\&vs=1519 (consultado el 08/01/2021).

${ }^{4}$ https://www.unwomen.org/es/news/in-focus/in-focus-gender-equality-in-covid-19-response/un-women-response-to-covid-19-crisis (consultado el 08/01/2021).

${ }^{5}$ https://www.ohchr.org/SP/hrbodies/cedaw/pages/cedawindex.aspx (consultado el 08/01/2021).

${ }^{6}$ https://www.ohchr.org/SP/hrbodies/cedaw/pages/cedawindex.aspx (consultado el 08/01/2021).

${ }^{7}$ https://www.ohchr.org/SP/hrbodies/cedaw/pages/cedawindex.aspx (consultado el 08/01/2021).
} 
adoptar medidas específicas dirigidas a las mujeres en situación de desventaja, (8) proteger a las mujeres y niñas en situaciones humanitarias y seguir aplicando la agenda de mujeres, paz y seguridad, y (9) fortalecer la respuesta institucional, la difusión de información y la recopilación de datos.

- El Instituto Europeo de Igualdad de Género (EIGE) ha realizado varios análisis de cómo la COVID-19 está impactando sobre la igualdad de género en diferentes áreas: trabajadores en primera línea ${ }^{8}$; impactos de género y salud ${ }^{9}$; trabajo no remunerado y tareas domésticas ${ }^{10}$, dificultades económicas y género ${ }^{11}$; violencia de género ${ }^{12}$; personas en vulnerabilidad ${ }^{13}$.

- A nivel estatal, el Instituto de la Mujer ha elaborado una guía "La perspectiva de género, esencial en la respuesta a la COVID-19"14.

- Igualmente se han realizado actuaciones de los organismos de igualdad autonómicos, aunque su análisis excede ya mucho de estas líneas.

Tomando en consideración las actuaciones de organismos de igualdad a todos los niveles que nos ponen en la pista de los problemas y sus posibles soluciones, nuestro análisis aborda las consecuencias de la enfermedad, del confinamiento y de la crisis subsiguiente en perspectiva de género y la respuesta dada por la normativa antipandemia dictada en España. Un análisis sometido a serios condicionantes. El primero es que, aún a día de hoy, no se conocen todavía las consecuencias de la enfermedad, el confinamiento o la crisis subsiguiente, pues estamos aún viviéndolas con no pocos sobresaltos (mutaciones del virus, sucesivas olas), lo que impide en muchas ocasiones alcanzar conclusiones definitivas. Y el segundo es que la normativa antipandemia es fruto de un auténtico big bang normativo por la vía de urgencia (lo que ha motivado cambios y ajustes de normas apenas aprobadas), con normas a todos los niveles (estatal, autonómico, municipal), y de gran multiplicidad (desde normas estatales con rango de ley hasta recomendaciones, guías y otros productos de soft law o cuasi normativos), lo que impide ofrecer un panorama completo de una normativa inmensa y que está en proceso de constante cambio.

Deudor de esos condicionantes, nuestro estudio solo pretende ser una aproximación general, en ocasiones construida sobre datos provisionales, al análisis en perspectiva de género sobre las consecuencias de la enfermedad, del confinamiento y de la crisis subsiguiente y la respuesta dada por la normativa antipandemia dictada en España, lo que acometeremos a través de un triple acercamiento: (1) las consecuencias de la enfermedad sobre la salud de las personas, en particular las personas dedicadas a los cuidados; (2) las consecuencias del confinamiento y medidas acordadas para combatir la enfermedad sobre

\footnotetext{
${ }^{8}$ https://eige.europa.eu/covid-19-and-gender-equality/frontline-workers (consultado el 08/01/2021).

${ }^{9} \mathrm{https}$ ///eige.europa.eu/covid-19-and-gender-equality/gender-impacts-health (consultado el 08/01/2021).

${ }^{10} \mathrm{https}$ //eige.europa.eu/covid-19-and-gender-equality/unpaid-care-and-housework (consultado el 08/01/2021).

${ }^{11} \mathrm{https}$ //eige.europa.eu/covid-19-and-gender-equality/economic-hardship-and-gender (consultado el 08/01/2021).

${ }^{12}$ https://eige.europa.eu/covid-19-and-gender-equality/gender-based-violence (consultado el 08/01/2021).

${ }^{13} \mathrm{https}$ //eige.europa.eu/covid-19-and-gender-equality/people-vulnerable-situations (consultado el 08/01/2021).

14 http://www.inmujer.gob.es/diseno/novedades/IMPACTO_DE_GENERO_DEL_COVID_19_(uv).pdf (consultado el 08/01/2021).
} 
los derechos con mayor dimensión de género, como la conciliación y la corresponsabilidad, o la violencia de género; (3) las consecuencias sociales, laborales y económicas derivadas de la enfermedad y/o de las medidas para combatirla desde una perspectiva de género.

\section{Las consecuencias de la enfermedad sobre la salud de las personas en perspec- tiva de género, en particular las personas dedicadas a los cuidados}

\subsection{Mortalidad masculina y mortalidad femenina: necesidad de una medicina en perspec- tiva de género}

El primer acercamiento a la pandemia atendiendo a las consecuencias de la enfermedad analizadas en perspectiva de género obliga a considerar el sexo de las víctimas. Las primeras aproximaciones realizadas durante la primera ola apuntaban hacia dos tendencias: hay más personas fallecidas del sexo masculino (lo que se ha justificado en que los hombres padecen más enfermedades intercurrentes; otras opiniones apuntan a diferencias del sistema inmunológico entre mujeres y hombres), mientras que hay más personas contagiadas del sexo femenino (lo que se ha justificado en que las mujeres se encuentran en la primera línea de lucha). Sin embargo, estas aproximaciones iniciales se sustentan en fallecimientos constatados por las Autoridades sanitarias con diagnóstico de COVID por la realización de test y utilizan estadísticas que aún no son definitivas (el Índice Nacional de Defunciones para 2020 ofrece todavía datos provisionales dada la existencia de retrasos en la notificación de decesos).

El Sistema de Monitorización de la Mortalidad Diaria del Instituto de Salud Carlos III $^{15}$, que opera sobre expectativas de mortalidad, revela que, en España en 2020, se ha producido un exceso de mortalidad por todas las causas del 10 de marzo al 9 de mayo superior en mujeres (72\%) que en hombres (67\%); y del 20 de julio al 20 de diciembre sigue siendo superior en mujeres (20\%) que en hombres (19\%). Algunas opiniones apuntan hacia la invisibilidad de fallecimientos de mujeres por COVID-19 al no habérseles realizado los test, o a fallecimientos por otras enfermedades que en etapas de normalidad sanitaria hubieran sido diagnosticadas y tratadas.

Pero el MoMo opera sobre expectativas de mortalidad usando datos provisionales sin considerar quienes han sido contagiados de COVID-19. Con lo cual, todavía es muy pronto emitir conclusiones seguras, salvo una conclusión que sí es segura: todos estos marcadores apuntan a diferencias por sexo que debemos primero identificar y después analizar si queremos ser efectivos desde la perspectiva sanitaria en la lucha contra la pandemia.

Y se deben identificar y analizar estas diferencias por sexo para no volver a caer en una Medicina solo para un sexo ${ }^{16}$, que históricamente ha sido el masculino pues los ensayos clínicos hasta no hace mucho se venían realizando con grupos de población integrados solo por hombres (como ha ocurrido con la mayoría de los antinflamatorios al uso con

\footnotetext{
${ }^{15}$ https://momo.isciii.es/public/momo/dashboard/momo_dashboard.html (consultado el 08/01/2021).

${ }^{16}$ Muy interesante al respecto la lectura de CARME VALLS LLOBET, Mujeres invisibles para la Medicina (Desvelando nuestra salud), (edición revisada), Ediciones Capitán Swing (Madrid, 2020).
} 
el argumento de no incluir a las mujeres para proteger su fertilidad o porque sus cambios hormonales alterarían los resultados), y también solo considerando a los varones se han elaborado los protocolos médicos (es conocido el caso del infarto cuyos protocolos hasta no hace tanto solo consideraban los síntomas del infarto en hombres, aunque son diferentes los síntomas en mujeres).

Detectar los diferentes efectos de la enfermedad sobre la salud de los hombres y de las mujeres es el paso fundamental para abordar la emergencia sanitaria en los diferentes individuos y comunidades, y el cimiento de una política de salud en igualdad. La investigación médica y los servicios de salud deben evaluar el impacto en los dos sexos (factores biológicos) y de los roles de género (factores sociales) en las diferencias de salud existentes entre mujeres y hombres para servir mejor las necesidades de salud de todas las personas individuales con independencia de su sexo.

No solo es exigencia requerida por la Medicina. También lo requiere el Derecho. Y es que la Ley Orgánica 3/2007, de 22 de marzo, para la igualdad efectiva de mujeres y hombres, en su artículo 27 lo dice claro:

"1. Las políticas, estrategias y programas de salud integrarán, en su formulación, desarrollo y evaluación, las distintas necesidades de mujeres y hombres y las medidas necesarias para abordarlas adecuadamente. 2. Las Administraciones públicas garantizarán un igual derecho a la salud de las mujeres y hombres, a través de la integración activa, en los objetivos y en las actuaciones de la política de salud, del principio de igualdad de trato, evitando que por sus diferencias biológicas o por los estereotipos sociales asociados, se produzcan discriminaciones entre unas y otros".

¿Se está haciendo de este modo en relación con el COVID-19? En concreto, ¿se está fomentando una investigación científica sobre el COVID-19 que atienda las diferencias entre mujeres y hombres en relación con la protección de su salud?, ¿se está garantizando la presencia equilibrada de mujeres y hombres en la investigación y en los puestos directivos y de responsabilidad profesional? ¿se están obteniendo y tratando desagregados por sexo los datos contenidos en registros, encuestas, estadísticas u otros sistemas de información médica y sanitaria? La provisionalidad de la situación nos impide llegar a conclusiones definitivas, pero debemos estar alerta, no solo porque estas cuestiones están siendo denunciadas por los organismos de igualdad, también porque el artículo 27 de la LOIEMH obliga a los poderes normativos a responder a todas estas cuestiones en el sentido de integrar la perspectiva de género.

2.2. Elevado índice de contagio femenino en las personas dedicadas a los cuidados: cuidar a quienes nos cuidan

En lo que respecta al elevado porcentaje de contagio femenino encuentra una de sus causas (quizás no sea la única, pero sin duda es muy relevante) en que entre quienes están 
mayormente en la primera línea de lucha contra la enfermedad encontramos colectivos altamente feminizados: el sector de la sanidad a todos los niveles (médicas, enfermeras o auxiliares), el sector de la dependencia (tanto la atención domiciliaria como en residencias de mayores), el cuidado de niños, el empleo en el hogar y el sector de limpieza. Todas estas personas trabajadoras, mayormente mujeres, van a estar en contacto con personas contagiadas en mayor medida que otros sectores profesionales. Y además el desbordamiento de la carga asistencial o el mayor estrés al que están sometidas, incide negativamente sobre su salud. Aquí nos encontramos con consecuencias negativas de la segregación profesional entre los sexos (las llamadas paredes de cristal). Una segregación profesional determinante de unas condiciones de empleo y trabajo inferiores a las de sectores masculinizados con empleos más seguros, mayores retribuciones y en general mejores condiciones de trabajo. Paradójicamente, las profesiones de cuidado son las más necesarias para el tratamiento de las personas enfermas y la contención de la enfermedad.

A la vista de estas consideraciones, hay un creciente consenso social e institucional en la necesidad de atribuir mayor valor al trabajo de cuidados en todas sus variantes. Un consenso que roza la unanimidad cuando la opinión emana de organismos de igualdad, pues se trata de un llamamiento que encontramos en ONU Mujeres, el EIGE o en el Instituto de la Mujer. "Cuidar a quien nos cuida" es el mensaje lanzado por la Valedora do Pobo de Galicia $^{17}$. Los desafíos crecientes a que se enfrentan las personas dedicadas al trabajo de cuidados deben conducir a una mejora de su reconocimiento social que debe traer aparejado una mejora de sus condiciones de trabajo, con empleos más estables y trabajos mejor remunerados en términos comparativos con otros trabajos de igual valor ${ }^{18}$.

\subsubsection{La prevención de riesgos laborales en servicios sanitarios y socio-sanitarios}

Para cuidar a quienes nos cuidan, lo primordial es garantizar su seguridad en el trabajo, y ello fue lo más perentorio durante la primera ola pues la fase inicial de la crisis sanitaria se caracterizó tanto en un plano jurídico por las limitaciones de una normativa de seguridad no especialmente diseñada para dar respuesta a una pandemia, como en un plano fáctico por la carencia de medios de protección y las dificultades de acceso a los mismos, lo que presentaba una trascendencia especialmente intensa en relación con el feminizado personal sanitario y sociosanitario.

${ }^{17}$ FERNÁNDEZ GALIÑO, M.D. "Cuidar a quien nos cuida”, https://www.valedordopobo.gal/es/essential_grid/articulo-de-la-valedora-do-pobo-dolores-fernandez-galino-cuidar-a-quien-nos-cuida-publicado-en-el-especial-del-dia25-de-julio-en-el-periodico-el-correo-gallego/ (consultado el 08/01/2021).

${ }^{18}$ MARTÍNEZ YAÑEZ, N.M. considera ineludible "cometer una revisión del trabajo en el sector sanitario y sociosanitario: es preciso enmendar las condiciones de trabajo y empleo, en particular, los salarios, la dimensión de las plantillas, la temporalidad y los términos de las contratas", siendo ineludible "por el derecho a la salud de la ciudadanía", y también "porque no queremos héroes ni heroínas, sino personas trabajadoras y trabajo decente", "Por una reconstrucción del mercado de trabajo con perspectiva de género", Hablemos de Feminismo - Falemos de Feminismo, página web de la Valedora do Pobo de Galicia (accesible en https://www.valedordopobo.gal/es/essential_grid/por-una-reconstrucciondel-mercado-de-trabajo-con-perspectiva-de-genero-por-nora-maria-martinez-yanez-profesora-contratada-doctoraacreditada-a-titular-de-derecho-del-trabajo-y-de-la-seguridad-soc/) (consultado el 08/01/2021). 
La normativa, no siempre con la premura exigible, se fue adecuando progresivamente, constituyendo actualmente una fenomenal masa de normas estatales y autonómicas, algunas generales otras para sectores, y ajustadas a la cambiante situación de cada momento (confinamiento, desescalada, nueva normalidad). Por ejemplo, en relación con las residencias de personas mayores y centros socio-sanitarios, a nivel estatal se han aprobado sucesivamente en el tiempo hasta tres normas diferentes con la finalidad de conseguir una ordenación más completa: la Orden SND/265/2020, de 19 de marzo, de adopción de medidas relativas a las residencias de personas mayores y centros socio-sanitarios, ante la situación de crisis sanitaria ocasionada por el COVID-1919; el Real Decreto-ley 9/2020, de 27 de marzo ${ }^{20}$; y la Orden SND/275/2020, de 23 de marzo, por la que se establecen medidas complementarias de carácter organizativo, así como de suministro de información en el ámbito de los centros de servicios sociales de carácter residencial en relación con la gestión de la crisis sanitaria ocasionada por el COVID-1921. Al lado de estas y de las demás normas estatales de carácter sectorial, y en esta ocasión con carácter general, también se deberá atender al "Procedimiento de actuación para los servicios de prevención de riesgos laborales frente a la exposición al SARS-CoV-2" editado por el Ministerio de Sanidad ${ }^{22}$.

En cuanto a la inicial carencia de medios de protección y las dificultades de acceso a los mismos, ello motivó reclamaciones judiciales con resultados relativamente contradictorios: algunas sentencias han desestimado la concurrencia de vulneración de derechos fundamentales por las empresas, dadas las circunstancias excepcionales derivadas de la pandemia, mientras que en otras se alcanza la conclusión contraria, al privilegiarse la salud de las personas afectadas; en otros casos se ha considerado concurría una carencia sobrevenida del proceso, en tanto que aunque inicialmente las empresas no habían proporcionado medidas de protección, sí lo habían hecho con posterioridad y con antelación al juicio ${ }^{23}$. Ciertamente, esa inicial carencia de medios de protección y las dificultades de

\footnotetext{
${ }^{19}$ Sintéticamente, la Orden SND/265/2020 regulaba la obligación de los trabajadores que tengan contacto directo con los residentes de seguir las medidas de protección recomendadas, según al nivel de riesgo al que están expuestos, recomendando, en la medida de lo posible, reducir al mínimo el número de trabajadores en contacto directo con un residente afectado, así como el tiempo de su exposición.

${ }^{20}$ Según su artículo 1, durante la vigencia del estado de alarma son servicios esenciales, cualquiera que sea la titularidad, pública o privada o el régimen de gestión, los centros, servicios y establecimientos sanitarios, que determine el Ministerio de Sanidad, y los centros sociales de mayores, personas dependientes o personas con discapacidad, que determine el Ministerio de Derechos Sociales y Agenda 2030. A tales efectos, deberán mantener su actividad, pudiendo únicamente proceder a reducir o suspender la misma parcialmente en los términos en que así lo permitan las autoridades competentes.

${ }^{21}$ Sintéticamente, la Orden SND/275/2020 establecía el mantenimiento obligatorio de la actividad, sin que se puedan adoptar medidas que conlleven el cierre, reducción o suspensión de actividades o de contratos laborales, salvo que la autoridad competente de la Comunidad Autónoma determine, por las circunstancias concurrentes, que el mantenimiento de la actividad del centro no es imprescindible. También la prioridad en la realización de pruebas diagnósticas de los residentes y del personal que presta servicio en los mismos, así como la disponibilidad de equipos de protección individual para ambos colectivos. Finalmente, la posibilidad de intervención en determinados supuestos de un centro residencial por las Comunidades Autónomas, con nombramiento de un empleado público para dirigirlo y coordinarlo.

${ }^{22}$ Accesible en https://www.mscbs.gob.es/profesionales/saludPublica/ccayes/alertasActual/nCov/documentos/ PrevencionRRLL_COVID-19.pdf (consultado el 08/01/2021).

${ }^{23}$ Sobre la situación jurisprudencial en esos iniciales momentos, FALGUERA BARÓ, M. La legislación laboral durante el estado de alarma, versión actualizada a 31/12/2020 (facilitada por el autor, a quien se lo agradecemos desde aquí), y a la versión anterior de 16/05/2020 se puede acceder en https://www.cograsova.es/blog/archivos/8935 (consultado el 08/01/2020), págs. 437 y 438.
} 
acceso, se pueden considerar superadas; pero no lo están los pleitos que ello puede originar, pues si se han producido contagios causantes de secuelas, quienes los hayan sufrido pueden acceder a prestaciones de incapacidad temporal o permanente, o sus causahabientes a prestaciones de muerte y supervivencia por su fallecimiento, con la posibilidad de reclamar recargos de prestaciones y responsabilidades a la empresa por incumplimiento de las medidas de seguridad e higiene en el trabajo.

\subsubsection{Presunción de laboralidad de los contagios COVID-19}

El Real Decreto-ley 19/2020, de 26 de mayo, por el que se adoptan medidas complementarias en materia agraria, científica, económica, de empleo y Seguridad Social y tributarias para paliar los efectos del COVID-19, introdujo una presunción de laboralidad de los contagios COVID-19 a favor del feminizado personal sanitario y sociosanitario, que se ha reiterado, con algunos cambios de redacción, en la disposición adicional $4 \stackrel{\text { a }}{\text { del Real }}$ Decreto-ley 28/2020, de 22 de septiembre, de trabajo a distancia. Tal presunción de laboralidad se realizaba bajo el mecanismo de asimilación al accidente de trabajo. Pero esto podía generar carencias de protección una vez que se constató que, tras la curación de la enfermedad, ha habido casos con secuelas importantes a veces en personas en que la enfermedad cursó con síntomas leves o de modo asintomático. De ahí la conveniencia de apreciar mejor una enfermedad profesional que permitiría dar cobertura de contingencia profesional a las prestaciones derivadas de esas secuelas.

A esta reivindicación de los colectivos afectados ha dado una respuesta parcial el Real Decreto-ley 3/2021, de 2 de febrero, por el que se adoptan medidas para la reducción de la brecha de género y otras materias en los ámbitos de la Seguridad Social y económico, que, en su artículo 6, regula las prestaciones causadas por las y los profesionales de centros sanitarios y socio sanitarios que durante la prestación de servicios sanitarios o socio sanitarios han contraído el virus SARS-CoV-2 en el ejercicio de su profesión. Y decimos una respuesta parcial porque las reivindicaciones estaban dirigidas a introducir la enfermedad derivada del COVID-19 en el listado de enfermedades profesionales, no como una asimilación temporal sin efectos permanentes, lo cual tiene consecuencias en orden a la intensificación de la vigilancia de la salud laboral pues esta comprende la detección de enfermedades profesionales no siendo claro si una asimilación como la que la norma hace tiene las mismas consecuencias.

La asimilación legal, primero a accidente de trabajo y ahora a enfermedad profesional, tiene limites personales, causales y temporales.

- Los límites personales se definen por referencia al personal que presta servicios en centros sanitarios o socio-sanitarios, inscritos en los registros correspondientes (Orden SCO/3866/2007, de 18 de diciembre, por la que se establece el contenido y la estructura del Registro General de centros, servicios y establecimientos 
sanitarios del Ministerio de Sanidad y Consumo; o, en su caso, en los registros de las Comunidades Autónomas).

Dado que no presta sus servicios en centros inscritos en ningún registro, quedaba excluido el personal sanitario de la inspección médica de los Servicios Públicos de Salud y del Instituto Nacional de la Seguridad Social y al personal sanitario de Sanidad Marítima que preste servicios en el Instituto Social de la Marina. El RDL 3/2021 ha cubierto esta carencia extendido la protección a ese personal (en su disposición adicional 3aㅡ).

Pero siguen quedando fuera otras situaciones merecedoras de igual protección, como ocurre el personal sociosanitario del hogar, pues obviamente este personal no presta servicios en ningún centro inscrito.

- Los límites temporales se definen por referencia a los contagios desde la declaración de la pandemia internacional por la OMS y hasta que las autoridades sanitarias levanten todas las medidas de prevención adoptadas para hacer frente a la crisis sanitaria ocasionada por el COVID-19. Término final un tanto difuso dados los visos de permanencia del virus.

- Los límites causales se definen por referencia al contagio de las personas incluidas en el ejercicio de su profesión y durante la prestación de servicios sanitarios o socio-sanitarios. No resulta relevante el régimen jurídico del personal a los efectos de aplicar la asimilación de laboralidad, con lo cual se podría aplicar tanto al contratado mediante un contrato de trabajo, o al que lo sea en régimen de autónomo. Tampoco resulta relevante si está contratado directamente por el titular del centro, o está contratado a través de contratas / subcontratas (aunque sea improbable que el personal prestador de servicios sanitarios o socio-sanitarios sea personal de contratas).

A los efectos de acreditar esta relación de causalidad, los servicios de prevención de riesgos laborales deberán emitir el correspondiente informe donde se haga constar que el personal de que se trata ha estado expuesto en el ejercicio de su profesión al virus SARSCoV-2 por la prestación de servicios sanitarios o socio-sanitarios. Queda, en consecuencia, la constatación probatoria de la relación de causalidad a la decisión de los servicios de prevención de riesgos laborales, que, si son externos, están habitualmente vinculados a la mutua que cubre las contingencias laborales.

Considerando todas estas exigencias causales no está cubierto todo el personal que presta servicios en centros inscritos, sino solo a las personas profesionales de medicina, enfermería y cuidadores y cuidadoras, o en general personal prestador de servicios sanitarios y socio-sanitarios. Con lo cual quedaría fuera los demás colectivos prestadores de otros servicios en el centro inscrito (limpieza, administración, mantenimiento), a quienes, ante un contagio de COVID-19 acaecido a causa de su trabajo, solo les quedaría la posibilidad de reclamar la declaración de accidente de trabajo en la modalidad de enfermedad / accidente del artículo 156.2.e) de la LGSS. 
2.3. Salud de las mujeres embarazadas, parturientas o en estado de lactancia, en particular la problemática transición entre las situaciones de riesgo y la situación de desempleo por un ERTE-COVID

Un aspecto muy relevante desde la perspectiva de la salud se encuentra en relación con las mujeres embarazadas, parturientas o en estado de lactancia. Aquí hay dos aspectos a considerar. De un lado, el riesgo, que afecta a todas las mujeres embarazadas, parturientas o en estado de lactancia, a la par que al feto o al recién nacido, de acudir a servicios hospitalarios para los exámenes prenatales, para el parto y para la estancia post-parto, en especial si los hospitales están saturados a consecuencia de pacientes con COVID-19. De otro lado, las especialidades requeridas para el tratamiento de la mujer embarazada, parturienta o en estado de lactancia, ya contagiada de COVID-19, más el riesgo de contagiar al recién nacido. Más que nunca en ambos aspectos se deberá estar en situación de pandemia a las recomendaciones de las autoridades sanitarias. El Ministerio de Sanidad ha elaborado una guía de acuerdo con las recomendaciones de la OMS: "Manejo de la mujer embarazada y el recién nacido con COVID-19"24. Pero el problema puede surgir por los riesgos de dispersión en la aplicación de estas medidas en hospitales públicos y privados y dada la transferencia de competencias de sanidad a las Comunidades Autónomas.

Desde el punto de vista de la prevención de riesgos laborales, el riesgo de exposición al contagio del COVID-19, que se ha calificado como un riesgo biológico de grado $3^{25}$ (una calificación que acaso se pueda quedar corta si se producen mutaciones del virus de más fácil propagación), puede conducir, en aplicación del artículo 26 de la Ley de Prevención de Riesgos Laborales, a una situación de riesgo durante el embarazo o de riesgo durante la lactancia natural, con la consiguiente suspensión del contrato de trabajo y el acceso a las prestaciones de Seguridad Social.

En relación con las prestaciones de riesgo durante el embarazo o la lactancia natural se ha planteado el problema de las transiciones entre esas situaciones y las prestaciones de desempleo derivadas de un expediente de regulación temporal de empleo a consecuencia de las medidas antipandemia, o viceversa. Ante las dudas generadas, la Dirección General de Ordenación de la Seguridad Social emitió a 17 de abril de 2020, una circular aclaratoria, destinada a las Mutuas colaboradoras, distinguiendo ${ }^{26}$ :

\footnotetext{
24 “Manejo de la mujer embarazada y el recién nacido con COVID-19”, versión actualizada a 17/06/2020, https:// www.mscbs.gob.es/profesionales/saludPublica/ccayes/alertasActual/nCov/documentos/Documento_manejo_embarazo_recien_nacido.pdf (consultado el 08/01/2021). Un análisis en CORTÉS BORDOY, J., “Embarazo, recién nacido y COVID-19", Medicina balear, vol. 35, núm. 3, págs. 35-38.

${ }^{25}$ La Directiva (UE) 2020/739 de 3 de junio de 2020 de la Comisión determinó la inclusión del SARS-CoV-2 en la lista de agentes biológicos que son patógenos humanos conocidos, incluyéndolo en el grupo 3 (por tanto: "agente patógeno que pueda causar una enfermedad grave en el hombre y presente un serio peligro para los trabajadores; existe el riesgo de que se propague en la colectividad, pero existen generalmente una profilaxis o un tratamiento eficaces"), en lugar del más grave grupo 4 ("agente patógeno que pueda causar una enfermedad grave en el hombre y suponga un serio peligro para los trabajadores; existen muchas probabilidades de que se propague en la colectividad; no existen generalmente una profilaxis o un tratamiento eficaces"); siguiendo idéntica lógica, tal modificación ha sido traspuesta en nuestro ordenamiento jurídico por la Orden TES/1180/2020 de 4 de diciembre de 2020.

${ }^{26}$ Dado que es una circular, no está publicada en el Boletín Oficial del Estado. Al texto se ha accedido en la página del Centro de Estudios Financieros: https://www.laboral-social.com/sites/laboral-social.com/files/oficio-DGOSS-prestacioon-riesgo-ERTE-17-04-20.pdf (consultado el 08/01/2021).
} 
(I) Trabajadora en riesgo durante el embarazo o la lactancia natural que se incluye dentro de un expediente de regulación temporal de empleo. Se plantea una aplicación analógica de lo establecido en los artículos 35 y 36 del Real Decreto $295 / 2009$, de 6 de marzo, por el que se regulan las prestaciones económicas del sistema de la Seguridad Social por maternidad, paternidad, riesgo durante el embarazo y riesgo durante la lactancia natural. En base a dicha analogía extensiva se resuelve: (1) Que si el ERTE supone la suspensión total de la actividad, se suspendería la prestación de riesgo durante el embarazo o la lactancia natural que se rehabilitaría al finalizar el ERTE. (2) Que si el ERTE supone una reducción de jornada, la suspensión afectaría a la parte de la jornada que se reduce.

(II) Trabajadora incluida dentro de un expediente de regulación de empleo pasa a riesgo durante el embarazo o la lactancia natural. En este caso, solo accedería a las prestaciones si el ERTE supone una reducción de jornada y las prestaciones se percibirán en atención a la jornada reducida.

Una circular aclaratoria que ya ha despertado unas severas y atinadas críticas. De entrada, los artículos 35 y 36 del RD 295/2009 se refieren al riesgo durante el embarazo. olvidando la existencia de disposiciones específicas para el riesgo durante la lactancia natural que, cuando menos, se debieron de citar: los artículos 49 a 51 del RD 295/2009. Y lo que en el fondo se hace es extender analógicamente disposiciones restrictivas de derechos (en contra del aforismo odiosa sunt restrigenda, favoralia sunt amplianda, que por lo demás encuentra apoyo en el artículo 9 de la CE).

Pero lo que más aquí nos interesa destacar, siguiendo a la doctrina más atenta, es que esta interpretación incurre en discriminación directa por razón de sexo, porque tiene un efecto restrictivo en el acceso a los derechos de Seguridad Social de trabajadoras (madres) por razón de la maternidad biológica, recibiendo un trato diferenciado y más perjudicial retributivamente que el que se da a otras modalidades de prestaciones percibidas mayoritariamente por trabajadores (varones), como es el caso de las prestaciones por incapacidad temporal (IT) derivada de contingencias profesionales, que no se ven afectadas por el pase de los trabajadores a situación de desempleo, ni en su cuantía ni es su extensión, según se deduce de lo establecido al respecto en el artículo 283 de la LGSS/2015 27.

Dos precisiones adicionales para consolidar esta solución alternativa a la contemplada en la circular. Una: la Directiva 92/85/CEE del Consejo, de 19 de octubre de 1992, relativa a la aplicación de medidas para promover la mejora de la seguridad y de la salud en el trabajo de la trabajadora embarazada, que haya dado a luz o en período de lactancia, establece, en su artículo 11, que si el Estado miembro decide cubrir los periodos de dispensa de trabajo por riesgos durante el embarazo o la lactancia natural con prestaciones públicas, su cuantía será adecuada cuando garantice unos ingresos equivalentes, como mínimo, a los que recibiría la trabajadora en caso de interrupción de sus actividades por

\footnotetext{
${ }^{27}$ POYATOS MATAS, G., "COVID y perspectiva de género, infancia y adolescencia. Conciliación de la vida laboral y familiar. Teletrabajo. Violencia de género", en Derecho laboral y de Seguridad Social COVID-19 (Un manual para juristas de trinchera)", Editorial Bomarzo (Albacete, 2020), pág. 186.
} 
motivos de salud (en la declaración anexa a la Directiva se aclara que es una remisión técnica, sin que se asimile el embarazo con una enfermedad).

Otra: la Sentencia del Tribunal Supremo, Sala de lo Social, de 10 de diciembre de 2014 (RCUD 3152/2013), resuelve la cuestión con claridad diáfana pues las normas legales y reglamentarias aplicables recogen de forma expresa las causas de extinción de la prestación, y entre ellas, en modo alguno se contempla la cesación de la actividad de la empresa.

\section{Las consecuencias del confinamiento y medidas acordadas para combatir la en- fermedad sobre los derechos con mayor dimensión de género}

Frente a la situación de pandemia, los poderes públicos han reaccionado con medidas diversas, en particular de confinamiento, lo que nos conduce a analizar cómo esas medidas, en particular el confinamiento, han afectado a las mujeres diferencialmente con los hombres. Bajo esta perspectiva de acercamiento, hay cinco temas de gran interés: (1) el incremento de las necesidades de conciliación atendiendo al cierre de las guarderías, colegios y, en general, centros educativos, así como por la reagrupación en muchos casos de los padres mayores en los domicilios de sus hijos/as; (2) el impacto del confinamiento sobre los regímenes de custodia y visitas de menores en matrimonios separados o divorciados, o parejas rotas; (3) el aislamiento al cual se han visto sometidas las víctimas de violencia de género en la pareja, dificultando la aplicación de las medidas para combatirla; (4) las situaciones de trata, explotación sexual y mujeres en contextos de prostitución; y (5) el acoso y violencia en el trabajo a distancia y el deber empresarial de prevención de riesgos.

\subsection{Impacto del confinamiento sobre la conciliación / corresponsabilidad}

El evidente impacto del confinamiento sobre la conciliación / corresponsabilidad ha merecido atención legislativa a nivel estatal. A estos efectos, el Real Decreto Ley 8/2020, de 17 de marzo, de medidas urgentes extraordinarias para hacer frente al impacto económico y social del COVID-19, ha adoptado dos medidas con evidente impacto de género, correspondiéndonos analizar (en línea con el objeto de nuestro estudio) si en su diseño legal se ha tomado en consideración la perspectiva de género.

3.1.1. El trabajo a distancia sin perspectiva de género en el RDL 8/2020 y su aparente superación por los RRDDLL 28/2020 y 29/2020

La primera de las medidas con impacto de género recogidas en el RDL 8/2020 es la preferencia del trabajo a distancia, obligando a la empresa a adoptar las medidas opor- 
tunas si ello es técnica y razonablemente posible y si el esfuerzo de adaptación necesario resulta proporcionado (artículo 5). Se trata de una medida cuya finalidad declarada (en la Exposición de Motivos) es mantener la actividad económica evitando los riesgos de contagio, pero que también tiene otra finalidad más oculta que es desplazar una parte del coste de los expedientes de regulación de empleo del Estado a las empresas (que no podrán acogerse a ellos si pueden adoptar trabajo a distancia), lo que se traduce en que, si está implantado por la empresa, la persona trabajadora deberá aceptarlo ${ }^{28}$. Ciertamente, el trabajo a distancia tiene una obvia perspectiva de género, pero en esta ocasión el fomento de la conciliación / corresponsabilidad no está en el fundamento de la medida, y ello se nota si nos paramos mientes en la restricción de la voluntariedad y asimismo en que se remite al entonces vigente artículo 13 del Estatuto de los Trabajadores, cuya parquedad reguladora y ausencia de perspectiva de género ha sido siempre puesta entre las causas de la muy escasa implantación del teletrabajo en España.

Pues bien, los estudios realizados en relación con el teletrabajo durante el confinamiento han puesto de relieve el mayor impacto que el trabajo a distancia ha tenido sobre las mujeres respecto de los hombres, tanto por la circunstancia de que, por la segregación profesional, los trabajos feminizados han sido más susceptibles de reconvertirse en teletrabajos, como por la circunstancia de que la distribución de roles en el hogar ha hecho recaer el trabajo de cuidados principalmente sobre las mujeres sometidas a una doble jornada doméstica: la derivada del teletrabajo y la derivada del trabajo doméstico ${ }^{29}$. En el fondo, la causa de esta situación han sido los roles de género (segregación profesional, reparto estereotipado de las tareas domésticas), pero también tiene su tanto de culpa una norma cuya perspectiva de género ni estaba ni se la esperaba.

El Real Decreto Ley 28/2020, de 22 de septiembre, de trabajo a distancia (aplicable a las relaciones laborales privadas), y el Real Decreto Ley 29/2020, de 29 de septiembre, de medidas urgentes en materia de teletrabajo en las Administraciones Públicas y de recursos humanos en el Sistema Nacional de Salud para hacer frente a la crisis sanitaria ocasionada por la COVID-19 (aplicable a las AAPP), han pretendido subsanar la parquedad normativa en que se hallaba sumida la regulación del teletrabajo, e igualmente han asumido la necesidad de adoptar la perspectiva de género.

\footnotetext{
${ }^{28}$ En este sentido de obligatoriedad para la persona trabajadora siempre que la empresa haya adoptado las medidas oportunas para su implantación, CASAS BAAMONDE, M.E., "El carácter preferente del trabajo a distancia en el estado de alarma y en la crisis sanitaria", Derecho de las relaciones laborales, núm. 7, Julio 2020, págs. 921-936, y LOUSADA AROCHENA, F., "El teletrabajo en la legislación de emergencia antipandemia", Revista de Jurisprudencia El Derecho, 30/11/2020, 8 págs.

${ }^{29}$ Según un Informe de Eurofound, el teletrabajo puede impactar de forma especialmente negativa en el trabajo de las mujeres poniendo en riesgo los avances conseguidos durante las últimas décadas en materia de igualdad de género (Living, working and COVID-19, COVID-19 series, Publications Office of the European Union, Luxembourg, 2020, pág. 4, accesible en https://www.eurofound.europa.eu/publications/report/2020/living-working-and-covid-19, consultado el 08/01/2020). Específicamente sobre la situación del confinamiento en España, FARRÉ, L. y GONZÁLEZ, L. concluyen que "durante el confinamiento, las mujeres han tenido que soportar una doble carga: más teletrabajo, combinado con un aumento en el volumen de las tareas domésticas", Las tareas domésticas y el cuidado de los hijos durante el confinamiento, una labor asumida principalmente por las mujeres, Observatorio Social de la Caixa (Septiembre 2020), accesible en https://observatoriosociallacaixa.org/-/las-tareas-domesticas-y-el-cuidado-de-los-hijos-durante-el-confinamientouna-labor-asumida-principalmente-por-las-mujeres (consultado el 08/01/2020).
} 
Ahora bien, ¿presentan estas normas una adecuada implementación de la perspectiva de género $?^{30}$ En cuanto al RDL 28, recupera el principio de voluntariedad en el acceso al trabajo a tiempo parcial (artículo 5), aunque mantiene la aplicación del RDL 8/2020 al trabajo a distancia implementado durante su vigencia (disp. trans. $3^{\mathrm{a}}$ ) rematada, por cierto, tres días antes de la publicación en el BOE del RDL $28^{31}$. También erige el principio de igualdad de trato y oportunidades y no discriminación en uno de sus principios reguladores (artículo 4), lo que es muy positivo, en especial por la referencia específica que, en ese mismo artículo 4, se realiza a la obligación empresarial de configurar y aplicar medidas contra el acoso sexual, acoso por razón de sexo, acoso por causa discriminatoria y acoso laboral; también la circunstancia de que esa misma norma salve expresamente la aplicación del artículo 34.8 del ET (derecho de las personas trabajadoras a adaptar la jornada y el trabajo por conciliación), lo que nos ofrece base para concluir que los derechos de conciliación justificarían una excepción de la voluntariedad en beneficio de la persona trabajadora, de ahí que esta podría solicitar a la empresa su implantación ${ }^{32}$.

No obstante, más allá de estas normas de principio demostrativas de la preocupación por asegurar que el trabajo a distancia no se convierta en una herramienta para ahondar en sesgos de género y por evitar un retroceso en los avances que se están consiguiendo en la materia, las medidas incorporadas al texto legal no parecen demasiado efectivas en la materia, dejando su concreción en gran medida a la negociación colectiva que, como apunta la doctrina más atenta, de momento no se siente concernida ${ }^{33}$.

En cuanto al RDL 29/2020, aunque afirme en su Exposición de Motivos que su regulación conecta con los contenidos del II Plan de Igualdad entre mujeres y hombres en la Administración General del Estado y en sus organismos públicos, aprobado por el Acuerdo del Consejo de Ministros de 20 de noviembre de 2015, lo cierto es que en su regulación (artículo 1, que introduce un artículo 47bis en el Estatuto Básico del Empelado Público) la

\footnotetext{
${ }^{30}$ La misma pregunta se plantea DE LA PUEBLA PINILLA, A., "Trabajo a distancia y teletrabajo: una perspectiva de género"; Labos Revista de Derecho del Trabajo y Protección Social, vol. 1, núm. 3: https://e-revistas.uc3m.es/index.php/ LABOS/article/view/5547/4115 (consultado el 08/01/2020).

${ }^{31}$ Según la disposición final $10^{a}$ del RDL 8/2020, la vigencia del artículo 5 alcanzaba hasta un mes después del fin de la vigencia de la declaración del estado de alarma. Pero el Real Decreto-ley 15/2020, de 21 de abril, de medidas urgentes complementarias para apoyar la economía y el empleo, estableció, en su artículo 15, que el contenido del artículo 5 del RDL 8/2020 se mantendría vigente durante los dos meses posteriores al cumplimiento de la vigencia prevista. Lo que supone (si lo entendemos bien) que la vigencia del artículo 5 del RDL 8/2020 alcanzaría hasta tres meses después del fin de la vigencia de la declaración del estado de alarma. Que, como se sabido, se produjo el 21 de junio, luego la vigencia del artículo 5 finalizó el 21 de septiembre. Además, el inciso final del artículo 15 del RDL 15/2020 estableció que, "en atención a las circunstancias, cabrán prórrogas adicionales por parte del Gobierno de lo establecido en el presente precepto", lo que supone (si lo entendemos bien, pues no es fácil desenvolverse en esta maraña legislativa de la normativa antipandemia) que el plazo de vigencia del artículo 5 del RDL 8/2020 ha resultado deslegalizado. En todo caso, el Gobierno no ha hecho uso de esta facultad.

${ }^{32}$ En este sentido, se manifiesta también LÓPEZ BALAGUER, M., "La voluntariedad del trabajo a distancia en el RDL 28/2020: ¿es el derecho al trabajo a distancia por conciliación una excepción?”, El Foro de Labos, https://forodelabos.blogspot.com/2020/10/la-voluntariedad-del-trabajo-distancia.html?utm_source=feedburner\&utm_medium=email\&utm_ca mpaign=Feed\%3A+ElForoDeLabos+\%28El+Foro+de+Labos\%29 (consultado el 08/01/2021).

${ }^{33}$ Para DE LA PUEBLA PINILLA, A., "no es buena señal que la primera regulación del trabajo a distancia (en convenio colectivo aprobado tras el RDL 28/2020), la recogida en el recientemente aprobado Convenio de Cajas de Ahorro, no contenga ni una sola referencia a esta cuestión ni, por tanto, contemple ninguna medida dirigida a evaluar y, en su caso, a evitar la incidencia del trabajo a distancia sobre el desarrollo y promoción profesional de las mujeres trabajadoras. Pero no debe decaer nuestro empeño, estamos a tiempo de mejorar" (DE LA PUEBLA PINILLA, A., “Trabajo ...", obra citada, pág. 11).
} 
implantación del teletrabajo depende de la aceptación de la Administración Pública pues la prestación del servicio mediante teletrabajo habrá de ser expresamente autorizada y será compatible con la modalidad presencial. Dado que la regulación se deja al desarrollo en la negociación colectiva ${ }^{34}$, esperemos que en ella se establezcan mejoras dirigidas a empoderar a las personas empleadas en la gestión de su tiempo.

Recapitulando, el teletrabajo implementado con una adecuada perspectiva de género no cabe duda alguna de que supondrá un avance en la conciliación y la corresponsabilidad. Pero si no utilizamos la perspectiva de género para su adecuada implementación, se puede convertir en una forma de potenciar la desigualdad como ya ha ocurrido durante la vigencia del artículo 5 del RDL 8/202035. En nuestras manos está hacerlo bien ahora.

\subsubsection{El Plan Mecuida}

La segunda de las medidas con impacto de género recogidas en el RDL 8/2020 (que está todavía vigente a la fecha de escribir estas líneas a diferencia de la preferencia por el teletrabajo ${ }^{36}$ ), el denominado Plan Mecuida (artículo 6) ${ }^{37}$, es el reconocimiento de un derecho de la persona trabajadora a la reordenación / reducción de la jornada de trabajo cuando su cónyuge, pareja o familiar de la persona trabajadora padezca el COVID-19, estuviera en centros educativos o de cuidado que hayan tenido que cerrar por causa del COVID-19, o cuando la persona que cuidaba al cónyuge, pareja o familiar no pudiera seguir haciéndolo por causa del COVID-19.

Seguramente a sabiendas de que estos derechos de conciliación suelen degenerar en un ejercicio femenino, se establece que el derecho previsto en este artículo es un derecho individual de cada uno de los progenitores o cuidadores, que debe tener como presupues-

\footnotetext{
${ }^{34}$ Muchas Comunidades Autónomas ya tenían regulaciones específicas: Decreto 92/2012 de 29 mayo (Euskadi); Decreto 82/2016 de 8 julio (Comunidad de Valencia); Decreto 16/2018 de 7 junio (Castilla y León); Decreto 36/2013 de 28 junio (Islas Baleares); Decreto 1/2018 de 10 enero (Extremadura); Decreto 57/2013 de 12 agosto (Castilla-La Mancha); Orden de 20 de diciembre de 2013 (Galicia).

${ }^{35}$ Parecidas conclusiones en DE LA PUEBLA PINILLA, A.: "La mayoría de los estudios realizados sobre el teletrabajo advierten del riesgo que este modo de prestación de servicios tiene desde la perspectiva de género y de la necesidad de que se adopten medidas para evitarlo. Apuntan incluso algunas fórmulas, no exentas de controversia, tales como ofrecer incentivos al uso por los trabajadores hombres del trabajo a distancia o asegurar el equilibrio entre géneros a la hora de asignarse la prestación de trabajo a distancia por las empresas ... Es esencial, por ello, que la inclusión social y económica de las mujeres esté en el corazón de las medidas de recuperación. La regulación del trabajo a distancia debería ser, en este sentido, una oportunidad para adoptar medidas que eviten la consolidación de esa tendencia que el desarrollo del teletrabajo durante el COVID-19 ha puesto de manifiesto" ("Trabajo ..., obra citada, pág. 11 passim).

${ }^{36}$ Pues aunque su vigencia era en principio la misma que la norma donde se establecía la preferencia por el teletrabajo, con lo cual su vigencia remataría el 21 de septiembre de 2020 (y nos remitimos a lo dicho al efecto en una nota anterior), el RDL 28/2020, en su disposición adicional 3ä, prorrogó la vigencia del artículo 6 del RDL 8/2020, en el que se regula el Plan MECUIDA, hasta el 31 de enero de 2021. Si tomamos en consideración que esa disposición adicional entró en vigor el 24 de septiembre de 2020 (según la disposición adicional 14a del RDL 28/2020), se observa la existencia de un impasse de tres días (entre el 21 de septiembre y el 24 de septiembre) en que el Plan Mecuida no estuvo formalmente vigente.

${ }^{37}$ Sobre el Plan Mecuida, véase AGUSTÍ MARAGALL, J., "Las excepcionales "medidas de conciliación laboral” en el artículo 6 del RDL 8/2020: Comentario de urgencia"; Revista Jurisdicción Social, núm. 209, 2009, págs. 14 a 24 (accesible en: http://www.juecesdemocracia.es/wp-content/uploads/2020/03/Revista-Social-MARZO-2020.pdf) (consultado el 08/01/2020).
} 
to el reparto corresponsable de las obligaciones de cuidado y la evitación de la perpetuación de roles. Parece encontrarse en esta finalidad la explicación de excluir los parientes por agnación, aunque la exclusión puede tener el efecto perverso de que la mujer trabajadora abandone el trabajo para cuidarlos, con lo cual sería peor el remedio que la enfermedad, y en este sentido ya se ha apuntado la necesidad de hacer una aplicación correctora ${ }^{38}$. A nuestro juicio, tampoco resulta factible (de hecho, la norma no lo dice expresamente, pero acaso esa conclusión se podría deducir de la invocación a la corresponsabilidad que en ella se contiene) que la implementación de la corresponsabilidad se haga a costa de facultar a la empresa, y en el caso de juicio a los órganos judiciales, a violentar el derecho fundamental a la privacidad de matrimonio, pareja o familia ${ }^{39}$.

¿Cómo se puede implementar la corresponsabilidad de que habla la norma? La cobertura económica de la reducción de jornada puede ser un incentivo adecuado para evitar que las diferencias salariales entre los miembros de un matrimonio o pareja (normalmente a favor del hombre) actúen como disuasorias del ejercicio masculino. Incluso sería factible vincular la cobertura a un ejercicio corresponsable (como se ha hecho en relación con el permiso por cuidado de lactante del artículo 37.4 del ET). Sin embargo, el RDL 8/2020 elude regular coberturas económicas, una laguna cubierta por algunas Co-

\footnotetext{
${ }^{38}$ Según POYATOS MATAS, G., "limitar los derechos laborales vinculados al cuidado, a un nexo sanguíneo no se corresponde con los principios internacionales que rigen en materia de Derechos Humanos (progresividad, universalidad, integralidad y pro persona), dado el incuestionable impacto constitucional que tiene el ejercicio de los derechos de conciliación familiar. Además, el mismo precepto en su párrafo tercero remite en relación al derecho de reducción de jornada al art. 37.6 del ET que sí incluye a los parientes afines. Ello generará problemas interpretativos en su aplicación que, bajo nuestro criterio, deberán solventarse integrando la perspectiva de género y de forma incluyente respecto a los familiares por afinidad, a tenor del mandato contenido en el art. 4 y 15 LOIEMH ... Otro argumento en favor de la interpretación extensiva lo hallamos en la Directiva 2019/1158 en cuyo art. 3.1.d) se define cuidador como el trabajador que dispensa cuidados o presta ayuda familiar o a una persona que viva en el mismo hogar que el trabajador y que necesite asistencia o cuidados importantes por un motivo médico grave, conforme a lo definido por cada Estado miembro, lo que incluso va más allá de la vinculación familiar por afinidad”, “COVID ...”, obra citada, págs. 166 y 167.

${ }^{39}$ Ciertamente, la corresponsabilidad es un deber legal de los cónyuges (CC, art. 68), y los derechos de conciliación se conciben en forma que fomenten la asunción equilibrada de las responsabilidades familiares (LO 3/2007, art. 44). Pero el incumplimiento del deber legal de corresponsabilidad se debe sancionar en el mismo ámbito jurídico en el que se erige como deber legal, esto es en el ámbito civil. Trasladar la sanción al ámbito laboral en forma de habilitar la negativa de la empresa a la solicitud de adaptación de la persona trabajadora sería algo totalmente disfuncional. De hecho, se estaría erigiendo a la empresa en una suerte de guardián de los deberes conyugales, o de los deberes existentes en la relación de pareja. Ninguna norma en nuestro ordenamiento jurídico habilita a la empresa a asumir tal potestad. También ello supondría indagar en la vida familiar de las personas trabajadoras en contra del derecho a la intimidad familiar (CE, artículo 18), sin que sea claro además el límite que a esa indagación se le podría establecer: ¿basta con analizar la corresponsabilidad en términos de dedicación temporal? ¿o debería asimismo analizarse en términos económicos y profesionales valorando lo que supondría que el cónyuge o la pareja reclamase en su trabajo la adaptación de la jornada que se le niega a la persona trabajadora solicitante? ¿sería legítimo analizar el reparto general de tareas domésticas y de cuidado dentro del matrimonio o la pareja para verificar la existencia de una descompensación por el hecho de asumir uno de los progenitores, y no el otro, una concreta tarea de cuidado determinante de la solicitud de adaptación? Hay además aspectos del equilibrio existente en los matrimonios y las parejas que son imponderables a la hora de hacer tal indagación, en cuanto están vinculados a afectos y sentimientos. En suma, no se debe permitir a la empresa la intromisión en la vida privada, convirtiéndola en una suerte de guardián de la corresponsabilidad (ni se les debe permitir a los Juzgados de lo Social), y así lo dice la doctrina judicial más atinada (SSTSJ/Galicia de 28-5-2019, Rec. Sup. 1492/2019, y de 22-7-2019, Rec. Sup. 1992/2019), también la mayoría de la doctrina científica: María Emilia CASAS BAAMONDE, "Soberanía sobre el tiempo de trabajo e igualdad de trato y de oportunidades de mujeres y hombres", Derecho de las Relaciones Laborales, núm. 3, 2019, págs. 1074-1075; MOLINA NAVARRETE, C., "Autodeterminación (soberanía) sobre el tiempo y adaptación de la jornada a la carta por razones conciliatorias: entre utopías, derechos y quimeras", Revista de Trabajo y Seguridad Social - CEF, núm. 441, 2019, pág. 11; LOUSADA AROCHENA, J.F., "El derecho a la adaptación de la jornada de trabajo con finalidad de conciliación (artículo 34.8 del ET)”, Actum Social, núms. 149-150, 2019, págs. 3-4 de 13; y POYATOS MATAS, G., “COVID y perspectiva ...”, obra citada, págs. 168 y 169 passim.
} 
munidades Autónomas ${ }^{40}$, lo que resulta loable aunque tiene el riesgo de la diversidad de regulaciones protectoras.

¿Qué ocurre en el ámbito del empleo público, en que no es aplicable el Plan Mecuida? La Resolución del Secretario de Estado de Política Territorial y Función Pública de medidas a adoptar en los centros de trabajo dependientes de la Administración General del Estado con motivo del COVID-19 de 10 de marzo $^{41}$ interpreta que el permiso para el cumplimiento de un deber inexcusable de carácter público y personal del artículo 48.j) del Estatuto Básico del Empleado Público resultaba de aplicación en los supuestos de necesidades familiares derivadas de la pandemia. Pero se trata de una regulación con problemas aplicativos: el artículo 48 del EBEP solo regula los permisos del personal funcionario; dicho permiso tiene una duración máxima de un mes; hay un agravio comparativo con respecto al resto de personas asalariadas del sector privado, en especial por lo que hace a la reducción de jornada, en tanto que en el caso de empleo público se siguen devengando las retribuciones ${ }^{42}$.

3.2. Regímenes de custodia y visitas de menores en matrimonios separados o divorciados, o parejas rotas

Un aspecto vinculado a la vida de las familias que se ha visto alterado por la situación de confinamiento ha sido en relación con el cumplimiento del régimen de custodia y visitas de menores en matrimonios separados o divorciados, o parejas rotas, dado el riesgo de contagio derivado de la entrega de los menores, y a su vez el temor del progenitor custodio, si no los entregan, de ser denunciado por incumplimiento.

Sobre la base del Real Decreto 463/2020, de 14 de marzo, de declaración del estado de alarma para la gestión de la situación de crisis sanitaria ocasionada por el COVID-19, esta problemática fue abordada en acuerdos gubernativos y en resoluciones jurisdiccionales del Poder Judicial.

Los Acuerdos de los Jueces de Familia de Barcelona de 18 de marzo de 2020 y de 24 de marzo de 2020, después de recordar que el Real Decreto declarando el estado de alarma no legitima el incumplimiento de resoluciones judiciales, por lo que se han de llevar a cabo y cumplir todos los sistemas de guarda, custodia, visitas y comunicaciones fijadas en las resoluciones judiciales vigentes, contenían las siguientes tres precisiones:

\footnotetext{
${ }^{40}$ Extremadura: Orden de 6 de julio de 2020 por la que se establecen las bases reguladoras de las ayudas a la contratación, como medida de fomento de la conciliación y corresponsabilidad de la vida personal, familiar y laboral para responder al impacto del COVID- 19 (DOE 09/07/2020); Castilla La Mancha: Decreto 32/2020, de 14 de julio, por el que se regula la concesión directa de ayudas para la conciliación de la vida familiar y laboral como consecuencia de la crisis originada por el COVID-19 (DOCM 17.07.2020); Islas Baleares: Orden de la Consejera de Asuntos Sociales y Deportes de 10 de agosto de 2020 por la que se establecen las bases reguladoras y la convocatoria extraordinaria de ayudas a la conciliación destinados a paliar los efectos de la COVID-19 (BOIB 11/08/2020); o Castilla y León: Decreto-ley 9/2020, de 10 de septiembre, por el que se adoptan medidas extraordinarias de apoyo a las personas y familias para la atención domiciliaria de menores, personas dependientes o con discapacidad que deban guardar confinamiento domiciliario a causa de la pandemia COVID 19 (BOCYL 14/09/2020).

${ }^{41}$ Accesible (tanto la Resolución de 10 de marzo, como otra aclaratoria de 12 de marzo) en: https://www.mptfp.gob. es/portal/prensa/actualidad/noticias/2020/03/20200311.html (consultada el 08/01/2020).

${ }^{42}$ Estas críticas las plantea FALGUERA BARÓ, M., La legislación ..., obra citada, pág. 50.
} 
(1) "los progenitores deberán observar, en todo caso, las normas de las autoridades gubernativas y sanitarias a los efectos de evitar la propagación del coronavirus, procurando un ejercicio responsable de la potestad parental y alcanzando los mayores acuerdos posibles, teniendo siempre presente que nos encontramos ante una situación excepcional y, por el momento, por un espacio de tiempo limitado";

(2) "si alguno de los progenitores presenta síntomas de contagio o ha resultado positivo en el test del COVID-19, en interés de los hijos menores (art. 9.2 LOPJM) y para evitar su propagación, es preferible que la guarda y custodia la ostente el otro progenitor, a fin de evitar su propagación al menor cuya custodia tiene confiada, debiéndose entenderse que, automáticamente concurre causa de fuerza mayor, que suspende provisionalmente, las medidas acordadas en el proceso en que se acordaron"; $y$

(3) "a fin de conseguir el necesario y deseable contacto paterno-filial el progenitor custodio deberá facilitar, particularmente por medios telemáticos (skype, facetime, o video llamada de whastapp) el contacto del/los hijo/s con el progenitor no custodio, siempre y cuando no se perturben las rutinas u horarios de descanso de los menores".

Acuerdo aplicado en algunas resoluciones de órganos judiciales barceloneses (Auto de 26/03/2020 del JPI 51 de Barcelona ${ }^{43}$ ). Otras resoluciones judiciales suspendieron los regímenes de visitas yendo un poco más allá, como ocurre con el Auto de 03/04/2020 del JPI 7 de Santa Cruz de Tenerife ${ }^{44}$, pues se lo suspendió al padre que trabajaba con enfermos de COVID-19, aunque no tenía síntomas y el test era negativo.

Si bien se plantearon dudas sobre la adecuación de estos acuerdos gubernativos y resoluciones jurisdiccionales del Poder Judicial con la Convención de los Derechos del Niño de Naciones Unidas (1989), no parece que esas dudas tengan mucha solidez habida cuenta de que el derecho del niño a relacionarse con sus progenitores (reconocido en el artículo 9) admite como excepción cuando a reserva de revisión judicial, las autoridades competentes determinen, de conformidad con la ley y los procedimientos aplicables, que tal separación es necesaria en el interés superior del niño, lo que vendría dado por el riesgo de contagio del virus.

Con la finalidad de restablecer el equilibrio en el régimen de visitas o custodia compartida cuando uno de los progenitores no haya podido atender en sus estrictos términos el régimen establecido y, en su caso, custodia compartida vigente, como consecuencia de las medidas adoptadas por el Gobierno y las demás autoridades sanitarias con el objeto de evitar la propagación del COVID-19, el Real Decreto Ley 16/2020, de 28 de abril, de medidas procesales y organizativas para hacer frente al COVID-19 en el ámbito de la Admi-

\footnotetext{
${ }^{43}$ Accesible en la página web del CGPJ, http://www.poderjudicial.es/search/documento/AN/9077980/Real\%20 Decreto\%20alarma\%20sanitaria\%20Covid-19/20200406 (consultado el 08/01/2021). También en El Derecho, Referencia EDJ 523/4404.

${ }^{44}$ Referencia El Derecho EDJ 2020/5230404.
} 
nistración de Justicia, estableció un procedimiento especial (artículos 3 a 6). Real Decreto Ley ya derogado, pero acaso debió mantenerse ese procedimiento en vigor en expectativa de la segunda ola.

\subsection{Impacto del confinamiento sobre la lucha contra la violencia de género en la pareja}

"Todos nos enfrentamos a importantes riesgos psicológicos debido al aislamiento o la cuarentena, pero las mujeres y a veces también los niños en domicilios no seguros viven una situación particularmente delicada", afirmó Evelyn Regner, presidenta de la Comisión de Derechos de la Mujer del Parlamento Europeo, el 7 de abril en una_rueda de prensa y añadió: "Debemos prestar atención a esta cuestión y ampliar las medidas para atajar la violencia contra las mujeres" ${ }^{\prime 4}$. La situación de las mujeres que sufren violencia de género es alarmante pues ha estado atrapadas con sus agresores, y previsiblemente lo seguirán estando. Hay mujeres cuya situación económica vulnerable las empuja a continuar con sus agresores $^{46}$.

Nos encontramos con una cuestión sobre la cual los organismos de igualdad a todos los niveles han manifestado su preocupación y que se ha visto corroborado en nuestro país por el incremento de las llamadas a los servicios de atención, pero no de las denuncias (a lo menos durante el confinamiento; con posterioridad seguramente se recuperen los números anteriores a la pandemia), y tampoco de los fallecimientos, que se han contenido acaso debido a la asunción por las mujeres de medidas de autoprotección en su relación con el agresor. Pero esto, lejos de ser positivo, viene a activar una bomba de relojería que puede estallar en cualquier momento, derivada del empoderamiento del agresor, a veces combinado con conductas adictivas, y el desgaste psicológico de la mujer.

El Ministerio de Igualdad reaccionó con un "Plan de Contingencia contra la violencia de género ante la crisis del COVID $-19^{\prime \prime 4}$ que es el antecedente del Real Decreto Ley $12 / 2020$, de 31 de marzo, de medidas urgentes en materia de protección y asistencia a las víctimas de violencia de género, cuya justificación, a decir verdad, se encuentra en la necesidad de modificar partidas presupuestarias que solo podrían serlo a través de normas con rango de ley (de hecho, a ello se dedica todo su Capítulo II). Su Capítulo I es el que recoge las medidas del Plan de Contingencia, a veces con mejoras. Resumidamente, las medidas adoptadas son las siguientes:

${ }^{45}$ Declaraciones de REGNER, E., https://www.europarl.europa.eu/news/es/press-room/20200406IPR76610/covid-19-medidas-contra-la-violencia-domestica-durante-el-confinamiento (consultado el 08/01/2021).

${ }^{46}$ Sobre estas situaciones, véase LORENTE ACOSTA, M., "Violencia de género en tiempos de pandemia y confinamiento", Revista española de Medicina Legal, 46(3), págs. 139-145, accesible en https://www.elsevier. es/es-revista-revista-espanola-medicina-legal-285-pdf-S0377473220300250 (consultado el 08/01/2020).

${ }^{47}$ Además del Plan (cuyo contenido ha sido sustituido por el RDL 12/2020), se impulsó una campaña institucional con el objetivo fundamental de concienciar contra la violencia de género y alertar ante situaciones de violencia dentro de los hogares durante el período de confinamiento. El material de la campaña está disponible en: http://www.violenciagenero.igualdad.gob.es/sensibilizacionConcienciacion/campannas/violenciaGobierno/todoSaldraBien/home.htm (consultado el 08/01/2020). 
- Declaración de servicio esencial de todos los servicios a los que se refieren los artículos 2 a 5 con los efectos del RD por el que se declara el estado de alarma, y normas de desarrollo (artículo 1 del RDL 12/2020).

- Garantía del normal funcionamiento de los servicios de información y asesoramiento jurídico 24 horas, telefónica y en línea, así como de los servicios de teleasistencia y asistencia social integral a las víctimas de violencia de género (artículo 2 del RDL 12/2020).

- Garantía del normal funcionamiento de los servicios de acogida a víctimas de violencia de género y otras formas de violencia contra las mujeres (artículo 3 del RDL 12/2020).

- Garantía del normal funcionamiento del sistema de seguimiento por medios telemáticos del cumplimiento de las medidas cautelares y penas de prohibición de aproximación en materia de violencia de género (artículo 4 del RDL 12/2020).

- Medidas relativas al personal que presta servicios de asistencia social integral a víctimas de violencia de género, y otras formas de violencia contra las mujeres que, por su naturaleza, se deban prestar de forma presencial (artículo 5 del RDL 12/2020).

- Campañas institucionales para prevenir la violencia de género durante el estado de alarma (artículo 6 del RDL 12/2020).

Desde luego, ninguna de las iniciativas señaladas sobra; sin embargo, y en este punto seguimos a la doctrina científica más atinada ${ }^{48}$, este texto legal no es del todo satisfactorio, ni mucho menos, y ello tanto por exceso, como por defecto. Lo primero, porque es una norma compleja (la lectura de su Exposición de Motivos es una tortura) que, al menos por lo que respecta al Capítulo I, es además excesiva, en el sentido de que ninguna de las medidas que en él se contemplan precisan de rango de ley. Lo segundo, por defecto, porque no tengo tan claro que esas medidas sean suficientes; por un lado, porque la actual situación de confinamiento y la falta de relación directa con otras personas ponen a la víctima de violencia de género en una situación de vulnerabilidad todavía mucho mayor de la que habitualmente es propia de esta situación; por otro, porque parece olvidar casi completamente a colectivos de mujeres que también sufren distintos tipos de violencia y que en esta situación están en una situación de mucho riesgo, como los colectivos de mujeres ancianas y las mujeres con discapacidad.

En fin, que sin desmerecer en nada lo que se ha hecho hasta el momento, se observan aspectos mejorables, y en todo caso y como siempre, la necesidad de una correcta aplicación de las normas para que estas acaben siendo útiles a sus finalidades. Recientes declaraciones de la Delegada del Gobierno para la Violencia de Género evidencian que "la pandemia nos está llevando a un peor trato institucional a las víctimas ${ }^{\prime 49}$.

\footnotetext{
${ }^{48}$ GARCÍA RUBIO, M.P., "De nuevo, la crisis del COVID-19 desde una perspectiva de género", Hablemos de Feminismo - Falemos de Feminismo, página web de la Valedora do Pobo de Galicia (accesible en https://www.valedordopobo. gal/es/essential_grid/de-nuevo-la-crisis-del-covid-19-desde-una-perspectiva-de-genero-por-maria-paz-garcia-rubiocatedratica-de-derecho-civil-universidad-de-santiago-de-compostela/ ) (consultado el 08/01/2021).

${ }^{49}$ Declaraciones de ROSELL AGUILAR, M.V., https://elpais.com/sociedad/2020-11-23/la-pandemia-nos-esta-llevando-a-un-peor-trato-institucional-a-las-victimas.html (consultado el 08/01/2021).
} 


\subsection{Víctimas de trata, explotación sexual y mujeres en contextos de prostitución}

Otras manifestaciones de violencia de género seguramente sufrirán transformaciones a causa de la pandemia: unas manifestaciones se potenciarán y otras se nos aparecerán en nuevos e inéditos escenarios. En este sentido, la delincuencia organizada se está adaptando a las debilidades sistémicas de las sociedades y de los poderes públicos con la finalidad de reorganizar las rutas de tráfico de personas y de encontrar otras nuevas formas de atraer a las posibles víctimas, principalmente mujeres, para ser explotadas sexualmente, y niñas (también niños) para pornografía infantil, aprovechando situaciones de vulnerabilidad, y priorizando las redes sociales como mecanismo de captación de las víctimas. También las víctimas de trata se enfrentan a daños aún mayores, entre otros motivos, por la necesidad de los propios traficantes de mantener sus ingresos a cualquier precio, con consecuencias de largo alcance para las víctimas.

Ante esta situación, el Ministerio de Igualdad ha aprobado una "Ampliación del Plan de Contingencia contra la violencia de género ante la crisis del COVID-19: medidas adicionales dirigidas a víctimas de trata, explotación sexual y a mujeres en contextos de prostitución"50. Las medidas a adoptar se han agrupado bajo seis epígrafes de los cuales los tres primeros son los que contienen medidas sustantivas:

(1) garantizar el derecho a la información para las víctimas de trata y explotación sexual y otras mujeres en contextos de prostitución mediante la difusión de los teléfonos 24 horas de entidades especializadas, del teléfono gratuito de la Policía Nacional específico de trata y de los correos electrónicos específicos de trata de la Policía Nacional y la Guardia Civil;

(2) garantizar la detección e identificación de las víctimas de trata y explotación sexual y de casos de extrema vulnerabilidad en contextos de prostitución mediante la implicación de las Fuerzas y Cuerpos de Seguridad del Estado en la detección de casos, fortalecer la coordinación entre las unidades policiales especializadas en trata y las ONG y reforzar el cauce de información a los servicios públicos especializados y a las ONG sobre posibles casos recibidos de desde servicios de migración y asilo; y

(3) garantizar la asistencia integral y protección de las víctimas de trata y explotación sexual, así como la atención a casos de especial vulnerabilidad mediante el mantenimiento de los servicios ambulatorios de asistencia integral a través de su declaración como servicios esenciales, mediante la garantía de alojamiento temporal seguro a las víctimas, disponiendo en caso necesario de establecimientos de alojamiento turístico, y asegurando una alternativa habitacional a mujeres que, sin encontrarse en una situación de riesgo, quedan en situación de necesidad habitacional a raíz de la crisis sanitaria, y mediante la facilitación

\footnotetext{
${ }^{50}$ Accesible en https://observatorioviolencia.org/wp-content/uploads/Plan-Viěctimas-trata_COVID_definitivo.pdf (consultado el 08/01/2020).
} 
del ingreso mínimo vital a mujeres que lo necesiten, en particular mujeres en situación irregular.

A estas tres medidas sustantivas se añaden otras tres organizativas o funcionales sobre una propuesta de modelo de acreditación para la solicitud del ingreso mínimo vital, el apoyo como beneficiarias de la medida de alternativa habitacional a las administraciones públicas y entidades que trabajan con víctimas de trata y explotación sexual, y las condiciones de trabajo para la ejecución de las medidas según los criterios sanitarios.

\subsection{Acoso y violencia en el trabajo a distancia y deber empresarial de prevención de riesgos}

Como otro ejemplo de potenciación de ciertas manifestaciones de violencia de género y/o de aparición de estas en nuevos e inéditos escenarios, la importante implantación del trabajo a distancia desde la llegada de la pandemia y los confinamientos domiciliarios nos ha alertado de situaciones que, hasta el momento, nos habían pasado inadvertidas a quienes nos dedicamos al derecho laboral, y que afectan a la igualdad ${ }^{51}$ :

1‥ La primera es la de que la violencia y el acoso tout court se manifiestan de una manera diferente cuando se canalizan a través de las modernas tecnologías de la información y la comunicación (por ejemplo, el comportamiento amenazador contra otra persona que lleve a esta a temer por su seguridad a través del establecimiento o intento de establecimiento de contacto a través de nuevas tecnologías, directamente o por medio de terceras personas, o a través del uso indebido de datos personales para adquirir productos o mercancías, para contratar servicios o para provocar que otras personas los contraten: es el ciberstalking, o ciberacoso).

$2^{a}$. La segunda es la de que, más en particular, la violencia de género se manifiesta de una manera diferente cuando se canaliza a través de las modernas tecnologías de la información y la comunicación (por ejemplo, el embaucamiento de niñas o mujeres adolescentes a través de nuevas tecnologías y en ocasiones usando una falsa identidad virtual, con la finalidad de obtener imágenes sexuales que ellas mismas facilitan, o más genéricamente con la finalidad de obtener cualquier avance sexual: es el comportamiento llamado grooming; o la difusión de imágenes sexuales, obtenidas legítimamente en el contexto de una relación sexual consentida que luego se rompe: es el revenge porn; o la amenaza de difundir imágenes ilícitamente obtenidas buscando ventajas sexuales: sería una

\footnotetext{
${ }^{51}$ Aunque es un estudio prepandemia, es de interés el estudio de DE STEFANO, V.; DURRI, I.; STYLOGIANNIS, C. y WOUTERS, M., Actualización de las necesidades del sistema: Mejora de la protección frente al ciberacoso y a la violencia y el acoso en el mundo del trabajo posibilitados por las TIC, Documento de trabajo de la Organización Internacional del Trabajo 1 (febrero 2020), accesible en https://www.ilo.org/wcmsp5/groups/public/---ed_protect/---protrav/---travail/ documents/publication/wcms_736237.pdf (consultado el 08/01/2021). Con posterioridad a la pandemia, ha llamado la atención sobre los riesgos laborales del teletrabajo relacionados con la violencia de género POYATOS MATAS, G., "COVID y perspectiva ...., obra citada, págs. 199 a 202.
} 
sextorsión). También la agresión puede no tener componente sexual, sino solo sexista (sexist hate speech o gendered hate speech).

$3^{\text {a }}$. La tercera de esas situaciones obedece a que, si el trabajo a distancia se presta en el domicilio, coinciden los espacios físicos en los cuales se realiza el trabajo y se desarrolla la violencia doméstica. Aunque aún es pronto para disponer de datos fiables que permitan conocer exactamente el alcance del problema, aparenta bastante evidente el riesgo de una intensificación de la violencia doméstica si ambos cónyuges o miembros de la pareja conviven más tiempo juntos en el domicilio común.

Todas estas situaciones existen en la realidad ordinaria de la vida y se ven posibilitadas si el trabajo es a distancia y, muy especialmente, si se trata de teletrabajo. En consecuencia, no sorprende que en el RDL 28/2020 (dentro del artículo 4, epigrafiado como "igualdad de trato y oportunidades y no discriminación") se establezca, en su artículo 4.4.I, que, de conformidad con lo previsto en la normativa aplicable, las empresas deberán tener en cuenta las particularidades del trabajo a distancia, especialmente del teletrabajo, en la configuración y aplicación de medidas contra el acoso sexual, acoso por razón de sexo, acoso por causa discriminatoria y acoso laboral; y, en su artículo 4.4.II, que, en la elaboración de medidas para la protección de las víctimas de violencia de género, deberán tenerse especialmente en cuenta, dentro de la capacidad de actuación empresarial en este ámbito, las posibles consecuencias y particularidades de esta forma de prestación de servicios en aras a la protección y garantía de derechos sociolaborales de estas personas ${ }^{52}$.

\section{Las consecuencias sociales, laborales y económicas derivadas de la enfermedad y/o de las medidas para combatirla}

Hay un tercer acercamiento a las consecuencias de la enfermedad y/o de las medidas para combatirla, y se puede reducir en apenas dos palabras: crisis económica, que ya está aquí, pero sus resultas todavía no se aprecian en todo su alcance. En la cual también aparece la óptica de género pues no es difícil identificar determinadas profesiones feminizadas a las cuales afectara sobre manera la crisis económica. Pensemos en la alta feminización del comercio, el turismo y la hostelería. Las empleadas de hogar es otro sector afectado al que no siempre llegan las ayudas públicas.

En general, las mujeres ocupan trabajos más precarios y peor remunerados: son una mayoría muy elevada en el trabajo a tiempo parcial (en España, alrededor del 75\%), y en muchos trabajos de temporada fijos discontinuos (en Galicia, en las conserveras), y el

\footnotetext{
${ }^{52}$ Sobre estas disposiciones, más ampliamente ver LOUSADA AROCHENA, J.F., “Prevención de riesgos en el trabajo a distancia (reconocimiento del derecho y modulaciones en su aplicación; prevención del acoso y la violencia de género; riesgos de exposición a pantallas de visualización)", en Puntos críticos en relación al teletrabajo (tras el RDL 28/2020, de 22 de septiembre (dirs.: SAGARDOY DE SIMÓN, I. y NÚÑEZ-CORTÉS CONTRERAS, P.), Editorial Dykinson (Madrid, 2021).
} 
porcentaje de mujeres en empleos temporales es superior al de hombres. Previsiblemente, los empleos más precarios sufrirán más las consecuencias de la crisis económica, y de nuevo sobre ello alertan todos los organismos de igualdad.

Paradójicamente, todos estos trabajos precarios están más expuestos al contagio que otros mejor remunerados económicamente y valorados socialmente. Se ha llamado la atención sobre lo paradójico de que las mujeres de la limpieza siguen yendo a trabajar a diario, con el consiguiente riesgo para su salud que otros empleados de esas mismas empresas no corren, o lo hacen un mucha menor medida; también los trabajadores varones equiparados que se dedican, por ejemplo, a la limpieza de ventanas y que estos días están exonerados de hacerlo; ellas no, siguen limpiando pomos, barandillas, interruptores de la luz, baños, para mayor tranquilidad de los que tienen que trabajar in situ y de los que están en sus casas dirigiendo al personal; sin duda, estas mujeres tienen un riesgo añadido ${ }^{53}$.

\subsection{Subsidio extraordinario para las empleadas de hogar}

Los esfuerzos legislativos realizados para salir al paso del impacto adverso de la crisis sobre colectivos feminizados tienen bastantes claros, pero también bastantes oscuros. Esto se puede apreciar paradigmáticamente con una de las medidas más claramente dirigidas a un colectivo feminizado. Nos estamos refiriendo al desempleo para las empleadas de hogar introducido en el Real Decreto Ley 11/2020, de 31 de marzo, por el que se adoptan medidas urgentes complementarias en el ámbito social y económico para hacer frente al COVID-19, en concreto artículos 30 a 32. Medida desde luego muy positiva pero también con aspectos oscuros ${ }^{54}$.

En primer lugar, porque es un subsidio extraordinario (así es cómo lo denomina la norma) que solo se concede a las personas que, estando de alta en el Sistema Especial de Empleados del Hogar antes de la entrada en vigor del estado de alarma (14/03/2020), se encuentren en una de las siguientes situaciones: (1) Hayan dejado de prestar servicios, total o parcialmente, con carácter temporal, a fin de reducir el riesgo de contagio, por causas ajenas a su voluntad, en uno o varios domicilios y con motivo de la crisis sanitaria del COVID-19. (2) Se haya extinguido su contrato de trabajo por la causa de despido recogida en el artículo 49.1.k) del Estatuto de los Trabajadores o por el desistimiento del empleador o empleadora, en los términos previstos en el artículo 11.3 del Real Decreto 1620/2011, de 14 de noviembre, por el que se regula la relación laboral de carácter especial del servicio del hogar familiar, con motivo de la crisis sanitaria del COVID-19.

En segundo lugar, porque estos hechos causantes deben acaecer antes del levantamiento del estado de alarma y un mes más (disp. fin. 12ª RDL).

\footnotetext{
${ }^{53}$ GARCÍA RUBIO, M.P., "Perspectiva de género en la pandemia del COVID-19", Hablemos de Feminismo - Falemos de Feminismo, página web de la Valedora do Pobo de Galicia (accesible en https://www.valedordopobo.gal/es/essential_ grid/perspectiva-de-genero-en-la-pandemia-del-covid-19-por-maria-paz-garcia-rubio-catedratica-de-derecho-civilde-la-universidad-de-santiago-de-compostela/ ) (consultado el 08/01/2021).

${ }^{54}$ Sobre este subsidio extraordinario, véase SANZ SÁEZ, C., "Sobre el subsidio extraordinario para las empleadas de hogar en la crisis del COVID-19”, Trabajo y Derecho, núm. 67-68.
} 
En tercer lugar, porque la cuantía del subsidio será el resultado de aplicar un porcentaje del setenta por ciento a la base reguladora diaria constituida por la base de cotización del empleado de hogar correspondiente al mes anterior al hecho causante, dividida entre 30, y no podrá ser superior al Salario Mínimo Interprofesional, excluida la parte proporcional de las pagas extraordinarias. Con lo cual, y dado que los salarios son reducidos en este sector (el salario bruto medio del personal doméstico es inferior al salario bruto medio de todas las ramas de actividad; las jornadas son mayormente a tiempo parcial ${ }^{55}$ ), el porcentaje reducirá aún más la compensación económica a la persona trabajadora.

En cuarto lugar, porque no cubre a las empleadas de hogar (permítasenos utilizar el femenino) que no estuvieran dadas de alta en seguros sociales, siendo un sector con un grado muy alto de informalidad.

Resumiendo, estamos ante una medida plausible, pero insuficiente y temporal, de modo que la situación precaria de las personas empleadas de hogar, mayoritariamente mujeres, sigue todavía pendiente de resolución.

4.2. Ausencia de perspectiva de género en medidas de apoyo a trabajadores, consumidores, familias y colectivos vulnerables

Mayores críticas merecen otros aspectos del RDL 11/2020 pues, siendo plausibles en un análisis neutro, sin embargo, olvidan totalmente la perspectiva de género. Se trata de una serie de medidas mayormente de corte civilista, dirigidas al apoyo a trabajadores, consumidores, familias y colectivos vulnerables, haciendo especial hincapié en aquellos que más lo necesitan: la suspensión de lanzamientos para hogares vulnerables sin alternativa habitacional (artículo 1), la prórroga extraordinaria de los contratos de arrendamiento de vivienda habitual (artículo 2), la moratoria de la deuda arrendaticia para personas arrendatarias de vivienda habitual en situación de vulnerabilidad económica (artículos 3 y 4), las medidas de apoyo al alquiler con líneas de avales públicos (artículo 9), la moratoria de las deudas hipotecarias para la adquisición de la vivienda habitual, o la moratoria para otros créditos y préstamos no hipotecarios que tengan las personas en situación de vulnerabilidad económica, particularmente los créditos al consumo (artículos 16 y siguientes). Pues bien, como ha puesto de manifiesto la mejor doctrina científica ${ }^{56}$, en las definiciones de vulnerabilidad contenidas en la norma a diversos efectos (en el artículo 5: definición de la situación de vulnerabilidad económica a efectos de obtener moratorias o ayudas en relación con la renta arrendaticia de la vivienda habitual; en el artículo 16: definición de vulnerabilidad económica a los efectos de la moratoria hipotecaria y del crédito de financiación no hipotecaria; y en el artículo 18: definición de la situación de vulnerabilidad económica y acreditación derivadas de los contratos de crédito sin garantía hipotecaria)

\footnotetext{
${ }^{55}$ El salario bruto medio total para el personal doméstico es un 58,9\% inferior al salario medio de todas las ramas de la actividad, y además un 51,6\% de las personas empleadas en el hogar lo están a jornada parcial. Datos tomados de POYATOS MATAS, G., “COVID y perspectiva ...”, obra citada, pág. 192.

${ }^{56}$ GARCÍA RUBIO, M.P., “De nuevo, la crisis ..., obra citada.
} 
no hay alusión directa alguna a la perspectiva de género, a pesar del carácter de principio informador del ordenamiento jurídico español que el artículo 4 de la LOIHM reconoce al principio de igualdad entre hombres y mujeres, cuando es que muchas de estas personas y muchos de estos hogares vulnerables son mujeres o están sustentados por mujeres; así sucederá en la gran mayoría de los casos de familias monoparentales, particularmente vulnerables también desde el punto de vista económico, y en personas ancianas que viven solas, asimismo mayoritariamente mujeres, o en las que viven dos o más ancianos y en los que también de modo principal la cuidadora es una mujer, y no hubiera estado de más que la norma aludiera directamente a este tipo de familias.

\subsection{Compatibilidad del subsidio por cuidado de menor y prestación por desempleo o cese de actividad durante la permanencia del estado de alarma}

Seguimos dentro del RDL 11/2020 para encontrar una solución, en este caso satisfactoria, a una cuestión puntual en materia de Seguridad Social, cuál es la relativa a la compatibilidad o incompatibilidad del subsidio por cuidado de menor y prestación por desempleo o cese de actividad durante la permanencia del estado de alarma. Pues bien, la problemática se resuelve de manera satisfactoria a favor de la compatibilidad en la disposición adicional 22ª del RDL 11/2020:

"Durante la permanencia del estado de alarma declarado por Real Decreto 463/2020, de 14 de marzo, por el que se declara el estado de alarma para la gestión de la situación de crisis sanitaria ocasionada por el COVID-19, el subsidio por cuidado de menores afectados por cáncer u otra enfermedad grave, que vinieran percibiendo los trabajadores por cuenta ajena a 14 de marzo de 2020, no se verá afectado por la suspensión del contrato y reducción de jornada que tengan su causa en lo previsto en los artículos 22 y 23 del Real Decreto 8/2020, de 17 de marzo, de medidas urgentes extraordinarias para hacer frente al impacto económico y social del COVID-19".

Se ocupa la norma de precisar adicionalmente la manera en que ello se cohonesta con la solicitud de un ERTE $^{57}$, así como de extenderles la compatibilidad que establece a los trabajadores por cuenta propia ${ }^{58}$.

\footnotetext{
${ }^{57}$ Así lo expresa la norma: "En estos casos, el expediente de regulación temporal de empleo que tramite el empresario, ya sea por suspensión de contratos o reducción temporal de la jornada de trabajo, solo afectara al trabajador beneficiario de este subsidio en la parte de la jornada no afectada por el cuidado del menor. Será, por tanto, compatible el percibo del subsidio por cuidado de menores afectados por cáncer u otra enfermedad grave, con la percepción de la prestación por desempleo que como consecuencia de la reducción de la jornada, afectada por un expediente de regulación temporal de empleo, pudiera tener derecho a percibir. A tal efecto, la empresa al tiempo de presentar la solicitud, indicará las personas que tengan reducida la jornada de trabajo como consecuencia de ser titular del subsidio por cuidado de menores afectados por cáncer u otra enfermedad grave, señalando la parte de la jornada que se ve afectada por el expediente de regulación temporal de empleo. Durante el tiempo que permanezca el estado de alarma no existirá obligación de cotizar, teniéndose el periodo por cotizado a todos los efectos".

${ }^{58} \mathrm{Y}$ es que lo dispuesto "será de aplicación a los trabajadores autónomos que vinieran percibiendo el subsidio por cuidado de menores afectados por cáncer u otra enfermedad grave a 14 de marzo de 2020".
} 
Aunque la literalidad de la disposición adicional $22^{\text {a }}$ se refiere a situaciones generadas con anterioridad a 14 de marzo de 2020, se ha apuntado con razón que, a pesar de la literalidad de la norma, este derecho debe entenderse extendido a las situaciones que pudieran generarse con posterioridad al 14 de marzo de 2020, siempre que se cumplan las restantes condiciones establecidas por la DA 22 RD-L 11/2020, pues debe integrarse la perspectiva de género y de la infancia por su doble impacto (nota al pie: las mujeres son quienes mayoritariamente usan este derecho y los sujetos causantes son menores) y evitar interpretaciones restrictivas del derecho ${ }^{59}$.

\subsection{El ingreso mínimo vital en perspectiva de género}

Una medida plausible impulsada por el Gobierno es el Real Decreto Ley 20/2020 de 29 de mayo, por el que establece el ingreso mínimo vital, con una regulación que sí que ha integrado la perspectiva de género de una manera bastante satisfactoria, aunque no esté exenta de alguna carencia.

1‥ La regulación ha integrado la perspectiva de género, en primer lugar, cuando se suavizan las exigencias para ser persona beneficiaria o para ser titular del ingreso mínimo vital a las mujeres víctimas de violencia de género o víctimas de trata de seres humanos y explotación sexual, así:

(1) cuando vivan solas o cuando compartan domicilio con una unidad de convivencia sin integrarse en ella, no se les exigirá el cumplimiento de los requisitos (exigidos con carácter general) de tener al menos 23 años y menos de 65 , estar unidas a otra por vínculo matrimonial o como pareja de hecho, o no formar parte de otra unidad de convivencia (artículo 4.1);

(2) no se las excluye del beneficio aun si son usuarias de prestación de servicio residencial, de carácter social, sanitario o sociosanitario, con carácter permanente y financiada con fondos públicos (artículo 4.2);

(3) no se les aplica la edad mínima exigida de 23 años en el supuesto de no integrarse la persona en una unidad de convivencia, sino que basta con que sean mayores de edad, esto es mayores de 18 años (artículo 5.2.II);

(4) a los efectos del requisito de acceso consistente en tener residencia legal y efectiva en España y haberla tenido de forma continuada e ininterrumpida durante al menos el año inmediato anterior a la fecha de presentación de la solicitud, se las exceptúa de ese plazo (artículo 7.1);

(5) a los efectos del requisito de acceso de que, cuando las personas beneficiarias formen parte de una unidad de convivencia, esta esté constituida de forma continuada durante al menos el año anterior a la presentación de la solicitud, se las exceptúa de ese plazo (artículo 7.3).

${ }^{59}$ POYATOS MATAS, G., “COVID y perspectiva ...”, obra citada, pág. 184. 
No se exige la inscripción como demandante de empleo, lo que supone la diferencia más sustancial entre la regulación del ingreso mínimo vital y la regulación de la renta activa de inserción contemplada en el Real Decreto 1369/2006, de 24 de noviembre, por el que se regula el programa de renta activa de inserción para desempleados con especiales necesidades económicas y dificultad para encontrar empleo, en relación con el Real Decreto $1452 / 2005$, de 2 de diciembre, por el que se regula la ayuda económica establecida en artículo 27 de la Ley Orgánica 1/2004, de 28 de diciembre, de medidas de protección integral contra la violencia de género.

En todos los casos, la acreditación de víctima de violencia de género se hará por cualquiera de los medios establecidos en el artículo 23 de la Ley Orgánica 1/2004, de 28 de diciembre, de Medidas de Protección Integral contra la Violencia de Género, y la de víctima de trata de seres humanos y de explotación sexual a través de un informe emitido por los servicios públicos encargados de la atención integral a estas víctimas o por los servicios sociales, o por cualquier otro medio determinado reglamentariamente (artículo 19.6). La quiebra de protección es la violencia oculta debido al miedo o reticencia a denunciar ${ }^{60}$, que, en lo que ahora se nos interesa destacar, impide o dificulta el acceso al ingreso mínimo vital ${ }^{61}$.

2o. La regulación ha integrado la perspectiva de género, en segundo lugar, cuando se valora la monoparentalidad, situación marcadamente feminizada, para elevar la cuantía del ingreso mínimo vital pues a la cuantía mensual derivada de la suma de la cuantía establecida en el caso de una persona individual más un 30\% de cada miembro adicional a partir del segundo hasta un máximo del 220\%, se sumará un complemento de monoparentalidad equivalente a un $22 \%$ por ciento de la cuantía establecida en el caso de una persona beneficiaria (artículo 10.2.c).

3‥ A estas situaciones donde se aparece el impacto de género de una manera muy directa, se debe añadir el impacto de género más difuso, pero no por ello menos importante, derivado de la feminización de la pobreza, con lo cual es muy previsible que el ingreso mínimo vital sea un ingreso marcadamente feminizado, y así es como lo ha previsto el propio Gobierno. De ahí que, con razón, se haya afirmado $^{62}$ que, si se gestiona por las administraciones públicas correctamente, existe financiación suficiente y se realizan con rigor los servicios de inspección y control para evitar fraudes, la renta mínima vital favorecería fundamentalmente a mujeres y sus hijos/as que se encuentran en situación de pobreza y exclusión social, suponiendo una forma más de lucha contra la desigualdad de oportunidades entre hombres y mujeres, contra la brecha salarial, aumentando las posibilidades de acceder a educación y mercado laboral por más mujeres.

\footnotetext{
${ }^{60}$ Siguiendo el contenido de la Macroencuesta en 2019 elaborada por el Observatorio de Violencia de Género, de las mujeres que han padecido violencia física o sexual solo un 32\% presentó denuncia, https://observatorioviolencia.org/ wp-content/uploads/Macroencuesta2019_Estudio_completo.pdf .

${ }^{61}$ Esta crítica en JIMENO JIMÉNEZ, F., “El ingreso mínimo vital en hogares unipersonales”, e-Revista Internacional de la Protección Social (e-RIPS), vol. V, núm. 2, 2020, págs. 77-93.

${ }^{62}$ Por POLLOS CALVO, C., "Mujeres y el ingreso mínimo vital. Repercusión en la violencia de género", Diario La Ley, núm. 9669, Sección Tribuna, 8 de Julio de 2020, Wolters Kluwer.
} 
Pero los estereotipos de género siempre encuentran resquicios donde se pueden infiltrar para acabar generando situaciones de desigualdad. Al respecto, la circunstancia (inusual en nuestro Sistema de Seguridad Social) de distinguir entre personas beneficiarias (artículo 4) y personas titulares del ingreso mínimo vital (artículo 5) obliga a establecer que "en el supuesto de que en una unidad de convivencia existieran varias personas que pudieran ostentar tal condición, será considerada titular la persona a la que se le reconozca la prestación solicitada en nombre de la unidad de convivencia" (artículo 5.3). No siendo muy difícil concluir que, debido a la distribución de roles de género en las unidades de convivencia, serán hombres quienes asuman la condición de titulares con su consiguiente empoderamiento dentro de la unidad de convivencia, quedando relegadas las mujeres a la condición de personas beneficiarias. Saliendo al paso de los supuestos donde este efecto perjudicial para las mujeres resulta más inicuo, el RDL 3/2021, de 2 de febrero, ha modificado el RDL 20/2020 para establecer (en un nuevo artículo 6 bis) que tendrán la consideración de personas beneficiarias que no se integran en una unidad de convivencia, o en su caso, de personas beneficiarias integradas en una unidad de convivencia independiente, aquellas que, conviviendo en el mismo domicilio con otras con las que mantuvieran alguno de los vínculos previstos para constituir una unidad de convivencia, estén en supuestos de violencia de género, separación, nulidad o divorcio, o ruptura de pareja de hecho, o en supuestos de desahucio o de inhabitabilidad del domicilio ${ }^{63}$.

Una última precisión se debe realizar, y tiene que ver más que con la regulación legal, con su ejecución práctica, pues las dificultades administrativas de implementación del ingreso mínimo vital están generando aspectos oscuros y no pocas frustraciones sobre una normativa que, en principio, es beneficiosa en general, y (no obstante algunas carencias imprevistas) desde una perspectiva de género en particular.

\section{5. ... Y dos conclusiones}

Todo lo expuesto solo ha pretendido ser una mera aproximación general, en ocasiones construida sobre datos provisionales, al análisis en perspectiva de género sobre las consecuencias de la enfermedad, del confinamiento y de la crisis subsiguiente y la respues-

\footnotetext{
${ }^{63}$ Artículo 6 bis. Situaciones especiales. 1. Tendrán la consideración de personas beneficiarias que no se integran en una unidad de convivencia, o en su caso, de personas beneficiarias integradas en una unidad de convivencia independiente, aquellas personas que convivan en el mismo domicilio con otras con las que mantuvieran alguno de los vínculos previstos en el artículo 6.1, y se encontraran en alguno de los siguientes supuestos: (a) Cuando una mujer, víctima de violencia de género, haya abandonado su domicilio familiar habitual acompañada o no de sus hijos o de menores en régimen de guarda con fines de adopción o acogimiento familiar permanente. (b) Cuando con motivo del inicio de los trámites de separación, nulidad o divorcio, o de haberse instado la disolución de la pareja de hecho formalmente constituida, una persona haya abandonado su domicilio familiar habitual acompañada o no de sus hijos o menores en régimen de guarda con fines de adopción o acogimiento familiar permanente. En el supuesto de parejas de hecho no formalizadas que hubieran cesado la convivencia, la persona que solicite la prestación deberá acreditar, en su caso, el inicio de los trámites para la atribución de la guarda y custodia de los menores. (c) Cuando se acredite haber abandonado el domicilio por desahucio, o por haber quedado el mismo inhabitable por causa de accidente o de fuerza mayor, así como otros supuestos que se establezcan reglamentariamente. En los supuestos previstos en los párrafos (b) y (c) únicamente cabrá la consideración como unidad independiente a que se refiere el presente apartado durante los tres años siguientes a la fecha en que se hubieran producido los hechos indicados en cada una de ellas.
} 
ta dada por la normativa antipandemia dictada en España. Algunos aspectos solo han sido apuntados, otros apenas desarrollados, y en general todos merecen una profundidad que la provisionalidad del momento impide alcanzar. Nuestro estudio tampoco ha pretendido ser exhaustivo, algo también difícil de conseguir en este momento en que, por los avatares de la pandemia, los poderes públicos siguen legislando sobre la materia, con continuos cambios. $Y$ hay cuestiones de gran importancia dejadas en el tintero, como las situaciones de discriminación múltiple interseccional (las mujeres mayores o con discapacidad, por poner dos ejemplos claros, han sufrido especialmente las consecuencias de la pandemia). Unas líneas de investigación que seguramente serán exploradas por la doctrina científica.

Pero nada de ello nos impide extraer dos conclusiones seguras: la pandemia pone en riesgo el nivel de igualdad de género alcanzado con anterioridad, pero también es oportunidad de mejora si los poderes públicos introducen la perspectiva de género en el corazón de la reconstrucción.

\section{Bibliografía}

AGUSTÍ MARAGALL, J. “Las excepcionales "medidas de conciliación laboral” en el artículo 6 del RDL 8/2020: Comentario de urgencia"; Revista Jurisdicción Social, núm. 209, 2009, págs. 14 a 24 (accesible en: http://www.juecesdemocracia.es/wp-content/ uploads/2020/03/Revista-Social-MARZO-2020.pdf) (consultado el 08/01/2020).

CASAS BAAMONDE, M.E. "Soberanía sobre el tiempo de trabajo e igualdad de trato y de oportunidades de mujeres y hombres", Derecho de las Relaciones Laborales, núm. 3, 2019.

- "El carácter preferente del trabajo a distancia en el estado de alarma y en la crisis sanitaria", Derecho de las relaciones laborales, núm. 7, Julio 2020.

CORTÉS BORDOY, J. “Embarazo, recién nacido y COVID-19”, Medicina balear, vol. 35, núm. 3, págs. 35-38.

DE LA PUEBLA PINILLA, A. “Trabajo a distancia y teletrabajo: una perspectiva de género”; Labos Revista de Derecho del Trabajo y Protección Social, vol. 1, núm. 3: https://erevistas.uc3m.es/index.php/LABOS/article/view/5547/4115 (consultado el 08/01/2020).

DE STEFANO, V.; DURRI, I.; STYLOGIANNIS, C. y WOUTERS, M. Actualización de las necesidades del sistema: Mejora de la protección frente al ciberacoso y a la violencia y el acoso en el mundo del trabajo posibilitados por las TIC, Documento de trabajo de la Organización Internacional del Trabajo 1 (febrero 2020), accesible en https://www.ilo.org/wcmsp5/groups/public/---ed_protect/---protrav/---travail /documents/publication/ wcms_736237.pdf (consultado el 08/01/2021).

EUROFOUND, Living, working and COVID-19, COVID-19 series, Publications Office of the European Union, Luxembourg, 2020, accesible en https://www.eurofound.europa.eu/ publications/report/2020/living-working-and-covid-19 (consultado el 08/01/2020). FALGUERA BARÓ, M. La legislación laboral durante el estado de alarma, versión actualizada a 31/12/2020 (facilitada por el autor), y a la versión anterior de 16/05/2020 
se puede acceder en https://www.cograsova.es/blog/archivos/8935 (consultado el 08/01/2020).

FARRÉ, L. y GONZÁLEZ, L. Las tareas domésticas y el cuidado de los hijos durante el confinamiento, una labor asumida principalmente por las mujeres, Observatorio Social de la Caixa (Septiembre 2020), accesible en https://observatoriosociallacaixa.org/-/lastareas-domesticas-y-el-cuidado-de-los-hijos-durante-el-confinamiento-una-laborasumida-principalmente-por-las-mujeres (consultado el 08/01/2020).

FERNÁNDEZ GALIÑO, M.D. "Igualdad, conciliación familiar y corresponsabilidad”, en la "Videoconferencia: Derechos sociales, ciudadanía y COVID-19", accesible en https:// www.fundacionibercaja.es/videoconferencia-derechos-sociales-ciudadania-y-covid-19 (consultado a 08/01/2021).

- "Cuidar a quien nos cuida", https://www.valedordopobo.gal/es/essential_grid/ articulo-de-la-valedora-do-pobo-dolores-fernandez-galino-cuidar-a-quien-nos-cuida-publicado-en-el-especial-del-dia-25-de-julio-en-el-periodico-el-correo-gallego/ (consultado el 08/01/2021).

GARCÍA RUBIO, M.P. “Perspectiva de género en la pandemia del COVID-19”, Hablemos de Feminismo - Falemos de Feminismo, página web de la Valedora do Pobo de Galicia (accesible en https://www.valedordopobo.gal/es/essential_grid/perspectiva-de-genero-en-lapandemia-del-covid-19-por-maria-paz-garcia-rubio-catedratica-de-derecho-civil-dela-universidad-de-santiago-de-compostela/) (consultado el 08/01/2021).

- "De nuevo, la crisis del COVID-19 desde una perspectiva de género", Hablemos de Feminismo - Falemos de Feminismo, página web de la Valedora do Pobo de Galicia (accesible en https://www.valedordopobo.gal/es/essential_grid/de-nuevo-la-crisis-del-covid-19-desde-una-perspectiva-de-genero-por-maria-paz-garcia-rubio-catedratica-dederecho-civil-universidad-de-santiago-de-compostela/) (consultado el 08/01/2021).

JIMENO JIMÉNEZ, F., "El ingreso mínimo vital en hogares unipersonales", e-Revista Internacional de la Protección Social (e-RIPS), vol. V, núm. 2, 2020.

LOPEZ BALAGUER, M. "La voluntariedad del trabajo a distancia en el RDL 28/ 2020: ¿es el derecho al trabajo a distancia por conciliación una excepción?", El Foro de Labos, https://forodelabos.blogspot.com/2020/10/la-voluntariedad-del-trabajo-distancia. html?utm_source=feedburner\&utm_medium=email\&utm_campaign=Feed\%3A+ElFo roDeLabos+\%28El+Foro+de+Labos\%29 (consultado el 08/01/2021).

LORENTE ACOSTA, M. "Violencia de género en tiempos de pandemia y confinamiento", Revista española de Medicina Legal, 46(3), págs. 139-145, accesible en https://www.elsevier.es/es-revista-revista-espanola-medicina-legal-285-pdf-S0377473220300250 (consultado el 08/01/2020).

LOUSADA AROCHENA, J.F. "El derecho a la adaptación de la jornada de trabajo con finalidad de conciliación (artículo 34.8 del ET)”, Actum Social, núms. 149-150, 2019.

- "El teletrabajo en la legislación de emergencia antipandemia", Revista de Jurisprudencia El Derecho, 30/11/2020.

- "Prevención de riesgos en el trabajo a distancia (reconocimiento del derecho y modulaciones en su aplicación; prevención del acoso y la violencia de género; ries- 
gos de exposición a pantallas de visualización)", en Puntos críticos en relación al teletrabajo (tras el RDL 28/2020, de 22 de septiembre (dirs.: SAGARDOY DE SIMÓN, I. y NÚÑEZ-CORTÉS CONTRERAS, P.), Editorial Dykinson (Madrid, 2021).

- "Prevención de riesgos en el trabajo a distancia (reconocimiento del derecho y modulaciones en su aplicación; prevención del acoso y la violencia de género; riesgos de exposición a pantallas de visualización", Revista Derecho Social y Empresa, núm. 14, 2021 (descargable gratuitamente en https://www.dykinson.com/revistas/revista-derecho-social-y-empresa/prevencion-de-riesgos-en-el-trabajo-a-distancia/9141/; (consultado el 28/04/2021).

MARTÍNEZ YAÑEZ, N.M. "Por una reconstrucción del mercado de trabajo con perspectiva de género", Hablemos de Feminismo - Falemos de Feminismo, página web de la Valedora do Pobo de Galicia (accesible en https://www.valedordopobo.gal/es/essential_grid/ por-una-reconstruccion-del-mercado-de-trabajo-con-perspectiva-de-genero-pornora-maria-martinez-yanez-profesora-contratada-doctora-acreditada-a-titular-dederecho-del-trabajo-y-de-la-seguridad-soc/) (consultado el 08/01/2021).

MOLINA NAVARRETE, C. “Autodeterminación (soberanía) sobre el tiempo y adaptación de la jornada a la carta por razones conciliatorias: entre utopías, derechos y quimeras", Revista de Trabajo y Seguridad Social - CEF, núm. 441, 2019.

OLMO GASCÓN, A.M. Aspectos estructurales y coyunturales en la crisis del empleo femenino en la etapa COVID, Editorial Bomarzo (Albacete, 2020).

POYATOS MATAS, G. "Mujeres y COVID-19”, Hablemos de Feminismo - Falemos de Feminismo, página web de la Valedora do Pobo de Galicia (accesible en https://www. valedordopobo.gal/es/essential_grid/mujeres-y-covid-19-por-gloria-poyatos-matas-magistrada-especialista-de-la-sala-de-lo-social-del-tribunal-superior-de-justicia-de-canarias/ ) (consultado a 08/01/2021).

- "COVID y perspectiva de género, infancia y adolescencia. Conciliación de la vida laboral y familiar. Teletrabajo. Violencia de género", en Derecho laboral y de Seguridad Social COVID-19 (Un manual para juristas de trinchera)", Editorial Bomarzo (Albacete, 2020).

POLLOS CALVO, C. "Mujeres y el ingreso mínimo vital. Repercusión en la violencia de género", Diario La Ley, núm. 9669, Sección Tribuna, 8 de Julio de 2020, Wolters Kluwer.

REGNER, E. Evelyn, Declaraciones en Prensa https://www.europarl.europa.eu/news/es/ press-room/20200406IPR76610/covid-19-medidas-contra-la-violencia-domestica-durante-el-confinamiento (consultado el 08/01/2021).

ROSELL AGUILAR, M.V. Declaraciones en El País, https://elpais.com/sociedad/2020-11-23/ la-pandemia-nos-esta-llevando-a-un-peor-trato-institucional-a-las-victimas.html (consultado el 08/01/2021).

SANZ SÁEZ, C. "Sobre el subsidio extraordinario para las empleadas de hogar en la crisis del COVID-19", Trabajo y Derecho, núm. 67-68.

VALLS LLOBET, C. Mujeres invisibles para la Medicina (Desvelando nuestra salud), (edición revisada), Ediciones Capitán Swing (Madrid, 2020). 